Article

\title{
Antimicrobial Activity and Degradation Ability Study on Nanoparticle-Enriched Formulations Specially Designed for the Neutralization of Real and Simulated Biological and Chemical Warfare Agents
}

Raluca-Elena Ginghina ${ }^{1}\left(\mathbb{D}\right.$, Gabriela Toader ${ }^{2, *} \mathbb{D}$, Munizer Purica ${ }^{3, *}$, Adriana-Elena Bratu ${ }^{1}$, Claudiu Lazaroaie ${ }^{1}$, Tudor-Viorel Tiganescu ${ }^{2}$, Ramona-Elena Oncioiu ${ }^{1}$, George-Ovidiu Iorga ${ }^{1}$, Florina-Lucica Zorila ${ }^{4,5}$ (D, Mihai Constantin ${ }^{4}\left(\mathbb{D}\right.$, Gabriel Craciun ${ }^{3}$, Florin Comanescu ${ }^{3}$ and Cosmin Romanitan ${ }^{3}$ (D)

check for updates

Citation: Ginghina, R.-E.; Toader, G.; Purica, M.; Bratu, A.-E.; Lazaroaie, C.; Tiganescu, T.-V.; Oncioiu, R.-E.; Iorga, G.-O.; Zorila, F.-L.; Constantin, M.;

et al. Antimicrobial Activity and

Degradation Ability Study on

Nanoparticle-Enriched Formulations Specially Designed for the

Neutralization of Real and Simulated Biological and Chemical Warfare Agents. Pharmaceuticals 2022, 15, 97 https://doi.org/10.3390/ ph15010097

Academic Editor: Serge Mordon

Received: 18 November 2021

Accepted: 8 January 2022

Published: 14 January 2022

Publisher's Note: MDPI stays neutral with regard to jurisdictional claims in published maps and institutional affiliations.

Copyright: (C) 2022 by the authors. Licensee MDPI, Basel, Switzerland. This article is an open access article distributed under the terms and conditions of the Creative Commons Attribution (CC BY) license (https:// creativecommons.org/licenses/by/ $4.0 /)$.
1 Research and Innovation Center for CBRN Defense and Ecology, 225 Oltenitei Ave., 041327 Bucharest, Romania; ginghinaraluca@gmail.com (R.-E.G.); adriana.bratu@nbce.ro (A.-E.B.); claudiu@nbce.ro (C.L.); ramona.oncioiu@nbce.ro (R.-E.O.); ovidiu.iorga@nbce.ro (G.-O.I.)

2 Military Technical Academy "Ferdinand I", 39-49 George Cosbuc Boulevard, 050141 Bucharest, Romania; tiganescu.viorel.t@gmail.com

3 National Institute for R\&D in Microtechnologies, 126A Erou Iancu Nicolae Street, 077190 Voluntari, Romania; gabriel.craciun@imt.ro (G.C.); florin.comanescu@imt.ro (F.C.); cosmin.romanitan@imt.ro (C.R.)

4 Horia Hulubei National Institute for Physics and Nuclear Engineering, 30 Reactorului Street, 077125 Magurele, Romania; florina.zorila@nipne.ro (F.-L.Z.); mconstantin@nipne.ro (M.C.)

5 Department of Genetics, Faculty of Biology, University of Bucharest, 91-95 Splaiul Indepententei, 050095 Bucharest, Romania

* Correspondence: nitagabriela.t@gmail.com (G.T.); munizer.purica@imt.ro (M.P.)

Abstract: The present work reveals a comprehensive decontamination study on real and simulated biological and chemical warfare agents (BCWA). The emphasis was on evaluating the antimicrobial activity against real biological warfare agents, such as Bacillus anthracis, and also the capacity of neutralizing real chemical warfare agents, such as mustard gas or soman, by employing three different types of organic solutions enriched with $\mathrm{ZnO}, \mathrm{TiO}_{2}$, and zeolite nanoparticles, specially designed for decontamination applications. The capacity of decontaminating BCWA was evaluated through specific investigation tools, including surface monitoring with the swabs method, minimum inhibitory (MIC) and minimum bactericidal concentration (MBC) evaluations, time-kill tests for microorganisms, and GC-MS for monitoring chemical agents on different types of surfaces (glass, painted metal, rubber, and cotton butyl rubber). These tests revealed high decontamination factors for BCWA even after only $10 \mathrm{~min}$, accomplishing the requirements imposed by NATO standards. At the completion of the decontamination process, the formulations reached $100 \%$ efficacy for Bacillus anthracis after 10-15 $\mathrm{min}$, for soman after 20-30 $\mathrm{min}$, and for mustard gas in an interval comprised between 5 and $24 \mathrm{~h}$ depending on the type of surface analyzed.

Keywords: Bacillus anthracis; antimicrobial activity; mustard gas; soman; decontamination; nanoparticles; $\mathrm{ZnO} ; \mathrm{TiO}_{2}$; zeolite

\section{Introduction}

Biological and chemical warfare agents (BCWA) for mass destruction have been used in military conflicts and, unfortunately, the risk of being used by terrorist organizations is imminent [1]. Both biological and chemical warfare agents can be designated as weapons of terror against civilians or weapons of intimidation for the soldiers [2].

The use of biological warfare agents became more refined during the 19th century due to the advancements of modern microbiology which made possible the isolation and production of considerable stocks of specific pathogens [3,4]. During the first World War, the use of Bacillus anthracis (anthrax) and Pseudomonas pseudomallei (glanders) as biological 
weapons was reported [2,4]. In the same conflict (World War I), chemical weapons were also employed, mustard gas accounting for $80 \%$ of all the chemical casualties [2].

Many pathogens cause health diseases; however, only few of them possess characteristics that allow them to be used as bioweapons. A biological agent used as a bioweapon has several features, including high lethality, communicability, fast and predictable action, ability to survive in the environment if it encounters its host, and resistance to destruction with air, water, and food purification methods [5]. Biological agents are usually designed to be susceptible to treatments or vaccines, which are only available to those who perform the attack and not accessible to the victims [5]. Modern bioengineering can hypothetically allow for accomplishing these malicious intentions by creating, for example, antibiotic-resistant strains of anthrax, reducing the time of incubation of smallpox, or combining agents such as Ebola virus and anthrax in order to develop new diseases [5].

Analogous weapons consisting of chemical warfare agents (CWA) that are usually capable of rapid incapacitation, sudden death, or permanent harmful effects on health [6] were intended for use in warfare as "mass destruction weapons". CWAs can be classified into nerve, blistering, choking, incapacitating/behavior altering, and blood/asphyxiant agents [2,6-10]. The main existing chemical threats involve easily synthesized chemical agents theoretically manufacturable on a large scale, such as nitrogen and sulfur mustards (e.g., yperite) or organophosphorus nerve agents (e.g., soman, sarin, tabun, or Vx) [7]. From these various types of CWAs, nerve agents are considered one of the most lethal chemical weapons due to their phosphorylating mode of action derived from their organophosphorus structure, which leads to mammalian acute toxicity and/or death [10].

Unfortunately, the ease of production and dissemination of BCWAs makes possible the idea of being used by terrorist attacks against civilians.

After their discovery, the inhuman aspect of these BC weapons was soon recognized and in 1925, the Geneva Protocol for the interdiction of the use of chemical or bacteriological methods of warfare was signed [2,9]. This protocol was followed by the implementation of "The Convention on the Prohibition of the Development, Production, Stockpiling, and Use of Chemical Weapons And on Their Destruction (CWC)" [11] and "The Convention on the Prohibition of the Development, Production and Stockpiling of Bacteriological (Biological) and Toxin Weapons and on their Destruction (BWC)" [12].

In this context, biological and chemical defense research implies finding solutions for the early identification of BCWA threats and also developing efficient countermeasures in the case of BCWA attacks. The conventions, namely CWC and BWC, did not forbid research in this field because numerous cases of BCWA utilization were reported over time [2,7,8,13-15], thus it is still indispensable to develop versatile methods for "on-site" efficient and sustainable neutralization of biological and chemical warfare agents. Due to the severe toxicity of the real biological and chemical warfare agents' class, various simulants [1] are sometimes employed in research studies. Even if the use of non-pathogenic microorganisms as simulants of Biological Warfare Agents (BWA-S) could be useful in the initial phase of the development of a new decontamination technology, BWA-S imply, however, some limitations because they may have in common some of the properties of the biological warfare agents, but they also have different antigens, proteomes, and genomes [5]. The simulants of chemical warfare agents (CWA-S) present the same advantages and disadvantages as BWA-S, ensuring proper safe circumstances for preliminary screenings of the decontamination efficacy. Nevertheless, it is still essential to perform extensive tests on real warfare agents, too, for the proper design of the new decontamination formulations and for an objective evaluation of their performances.

When encountering a BCWA event, it is crucial to immediately decontaminate the exposed area to an acceptable level, thus victims can be located and treated [1,3]. Further decontamination steps may be required to reestablish the functionality of facilities or equipment. For large contaminated zones, rapid and effective methods for the neutralization and removal of toxic biological and chemical warfare agents is imperative to restore the combat effectiveness of the strategic elements (equipment, facilities, and personnel) [1,16]. 
During the past decades, various decontamination methods were developed by researchers for the neutralization of BCWA. Hydrolysis or oxidation by aqueous-based decontamination solutions proved their efficiency against BCWA but the quantity of wastewater generated post-decontamination is significant and requires expensive disposal. Limiting effluent volumes represents an imperative goal [7]. Consequently, organic neutralizing solutions (e.g., alcoholic) offer attractive approaches because this method involves lower amounts of post-decontamination waste [7].

Modern decontamination techniques also involve the use of the benefits brought by nanotechnology. In this regard, choosing the proper active nanosized ingredients could lead to higher BCWA decontamination performances. Several studies revealed the positive influence of various types of nanostructures on the neutralization of BCWA [10,17-22]. Numerous studies revealed that the presence of metal or metal oxides into a decontamination system favors achieving a selective and low temperature degradative process of BCWA [10].

From the wide variety of nanoparticles described in literature as active agents for BCWA neutralization, the antibacterial activity $[20,23,24]$ of zinc oxide nanoparticles and their capacity for neutralizing chemical warfare agents [25-27] received significant interest. $\mathrm{ZnO}$ is considered a bio-safe substance that possesses photo-oxidizing and photocatalysis effects on chemical and biological species [24]. Bactericidal and bacteriostatic mechanisms of $\mathrm{ZnO}$ nanoparticles can be attributed to the presumable generation of reactive oxygen species (ROS) and to the permeation of the cell membrane to toxic dissolved zinc ions [24]. Zinc oxide nanomaterials have been also reported to be successfully used as reactive sorbents for the detoxification of sulfur mustard [27] or nerve agents [26].

Another nanomaterial which attracted great interest for BCWA inactivation is represented by titanium dioxide [28-31]. $\mathrm{TiO}_{2}$ is a remarkable photocatalyst widely used for its antibacterial action due to its high photosensitivity, high efficiency, non-toxic nature, strong oxidizing ability, relative cheapness, and chemical stability [31]. Titanium dioxide nanoparticles are in fact one of the most studied materials for antimicrobial applications due to its bactericidal photocatalytic activity, safety, and self-cleaning properties. The mechanism of antimicrobial action of $\mathrm{TiO}_{2}$ is commonly associated to reactive oxygen species (ROS) with high oxidative abilities which affect bacterial cells by different mechanisms, leading to their death [32]. The increased surface area of $\mathrm{TiO}_{2}$ nanoparticles makes them suitable as antimicrobial agents because it increases the possibility of interaction with pathogenic bacteria. Moreover, their nanometric size allows them to easily enter through the membrane of the targeted microorganisms and damage their structure from the interior [30]. The photocatalytic activity of $\mathrm{TiO}_{2}$ brings multiple advantages also for the neutralization of chemical warfare agents through photodegradation mechanisms and the generation of ROS [18]. The large specific surface of nanosized titanium dioxide and the presence of surface hydroxyl groups allows for the efficient decontamination of chemical agents such as sulfur mustard and sarin, forming non-toxic products such as thiodiglycol and isopropyl methyl phosphonic acid, respectively [18].

A unique class of materials, which is widely utilized as adsorbents for various types of contaminants, is represented by zeolites. Their well-defined porous structure recommends them for various applications in catalysis, ion exchange, and adsorption processes [33]. Clinoptilolite (Cp) is a type of zeolite suitable for BCWA decontamination applications due to its distinctive features and advantages such as its low cost, availability, and most abundant natural zeolite [34]. Several toxicological studies proved that zeolites are nontoxic [33]. Even so, zeolites can be ion exchanged with $\mathrm{Ag}\left({ }^{+}\right), \mathrm{Zn}\left({ }^{2+}\right)$, or $\mathrm{Cu}\left({ }^{2+}\right)$ ions, or they can be employed in a decontamination solution containing other active ingredients to acquire antimicrobial properties or ion-releasing characteristics for providing prolonged or stronger activity [35]. $\mathrm{Ag}^{+}$ion-exchanged clinoptilolite zeolite has been reported to promote CWA-S (e.g., chloroethyl ethyl sulfide and dimethyl methyl phosphonate) adsorption and degradation [34]. 
Considering all the drawbacks of the existing decontamination methods and inspired by the recent findings in the field of BCWA, this paper proposes novel solutions, consisting of innovative nanoparticle-enriched formulations specially designed for the inactivation of real and simulated biological and chemical warfare agents. The novelty of this work consists of the multivalent character of the proposed decontamination formulations (suitable for both biological and chemical warfare agents) and the comprehensive evaluation of their efficacy against one real biological agent (Bacillus anthracis) as well as two real warfare agents (sulfur mustard and soman). Since the studies found in literature were carried out mostly on simulants, as far as we are concerned, we can affirm that this paper is the first one comprising extensive decontamination studies on real biological and chemical warfare agents performed on various types of surfaces according to NATO standards. The new formulations herein reported are comprised of an active organic solution as dispersion media and one of three types of nanosized adsorbents, namely $\mathrm{ZnO}, \mathrm{TiO}_{2}$, and zeolite, employed for the enhancement of the decontamination performances of the organic solution (higher antimicrobial activity and higher capacity for neutralizing chemical warfare agents).

\section{Results}

The decontamination solutions employed in this study were comprised of three types of nanoparticles: $\mathrm{ZnO}, \mathrm{TiO}_{2}$, and zeolite (the sample IDs are summarized in Table 1). As it will be further discussed in detail, the presence of these nanosized adsorbents in the organic solution proved that they could enhance the BCWA decontamination capacity. Figure 1 illustrates SEM images captured on each type of the three synthesized nanoparticles.

Table 1. Composition of the decontamination solutions.

\begin{tabular}{|c|c|c|c|}
\hline Sample ID & $\mathrm{ZnO}$ (wt.\%) & $\mathrm{TiO}_{2}$ (wt. \%) & Zeolite (wt.\%) \\
\hline DS & 0 & 0 & 0 \\
\hline DS-ZnO-0.5 & 0.5 & 0 & 0 \\
\hline DS-ZnO-1 & 1 & 0 & 0 \\
\hline DS- $\mathrm{TiO}_{2}-0.5$ & 0 & 0.5 & 0 \\
\hline DS- $\mathrm{TiO}_{2}-1$ & 0 & 1 & 0 \\
\hline DS-Z-0.5 & 0 & 0 & 0.5 \\
\hline DS-Z-1 & 0 & 0 & 1 \\
\hline
\end{tabular}

The size distribution of the nanoparticles was assessed using VegaTC software provided by Tescan and are displayed in Figure 2. The mean particle diameter is highlighted in the histograms (green bars).

Furthermore, characterization of nanoparticles distributions by EDX mappings were made and the results are illustrated in Figure 3 and Figure S1 (from the Supplementary Material File). These SEM and EDX analyses revealed the proportions of particles clusters (associations), their morphology, and also their composition.

XRD patterns of the synthesized nanoparticles are depicted in Figure 4. These graphs were obtained by employing the PXRD technique (powder X-ray diffraction), which is a rapid technique that measures the diffraction pattern of crystalline material.

Figure 5 presents the Raman spectra recorded for each of the synthesized nanoparticles, which were further employed as active components in the decontamination solutions. Figure 6 is comprised of the Raman spectra of the neat organic decontamination solution.

After obtaining the decontamination solutions, their efficiency against real and simulated biological and chemical warfare agents was evaluated through specific procedures, as detailed in the Methods section. Initially, an extensive evaluation of the antimicrobial activity of the neat organic decontamination solution was performed, followed by a comparative evaluation of the neutralization efficacy of the NPs-based solutions. These tests were performed on real biological warfare agents (e.g., Bacillus anthracis) and also on other microorganisms which can be considered as simulants for various types of biological agents. Firstly, a controlled contamination was performed and the values obtained are presented 
in Table 2. Afterwards, the decontamination solution was applied on the contaminated samples. The results obtained after the completion of the decontamination process are illustrated in Table 3.
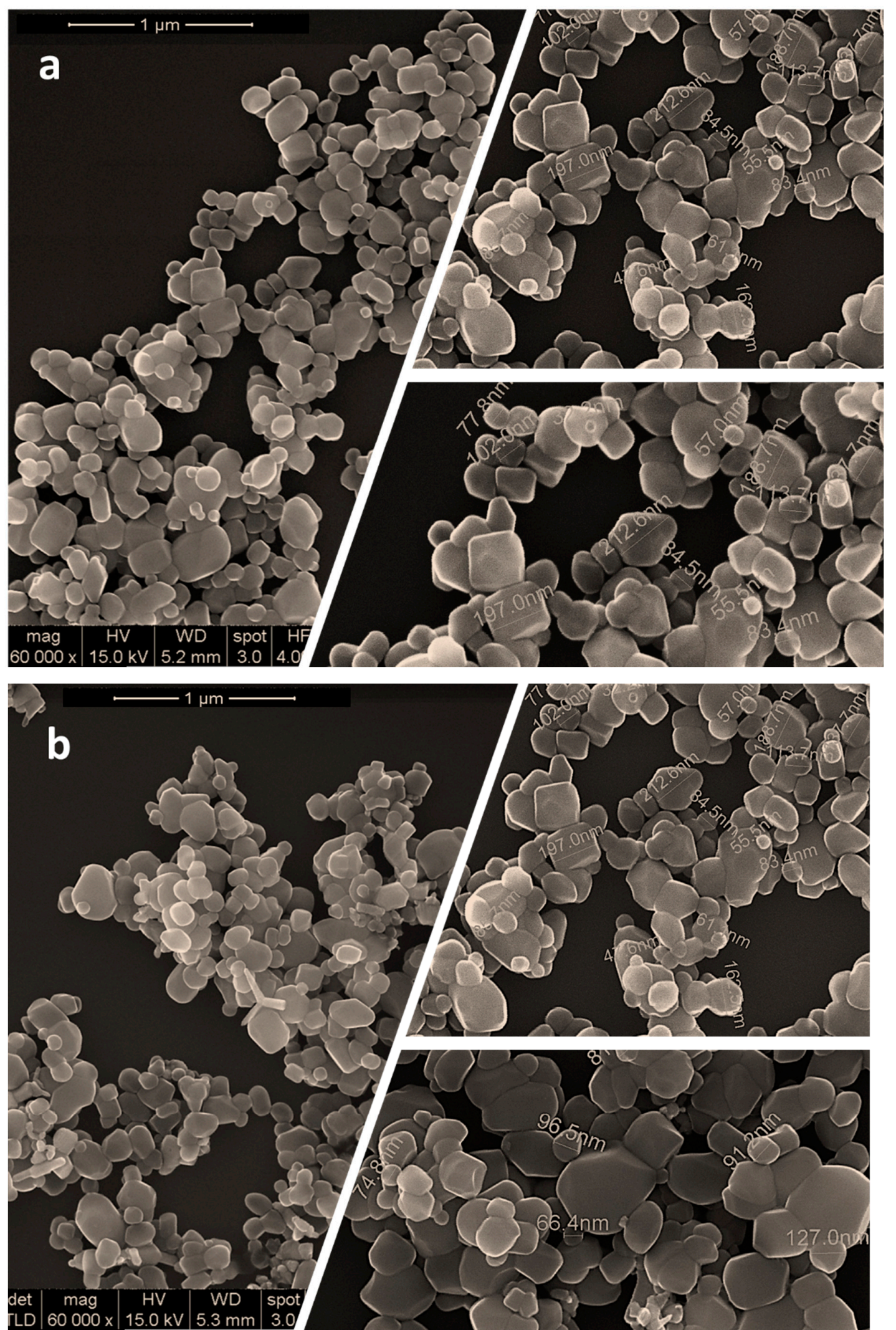

Figure 1. Cont. 


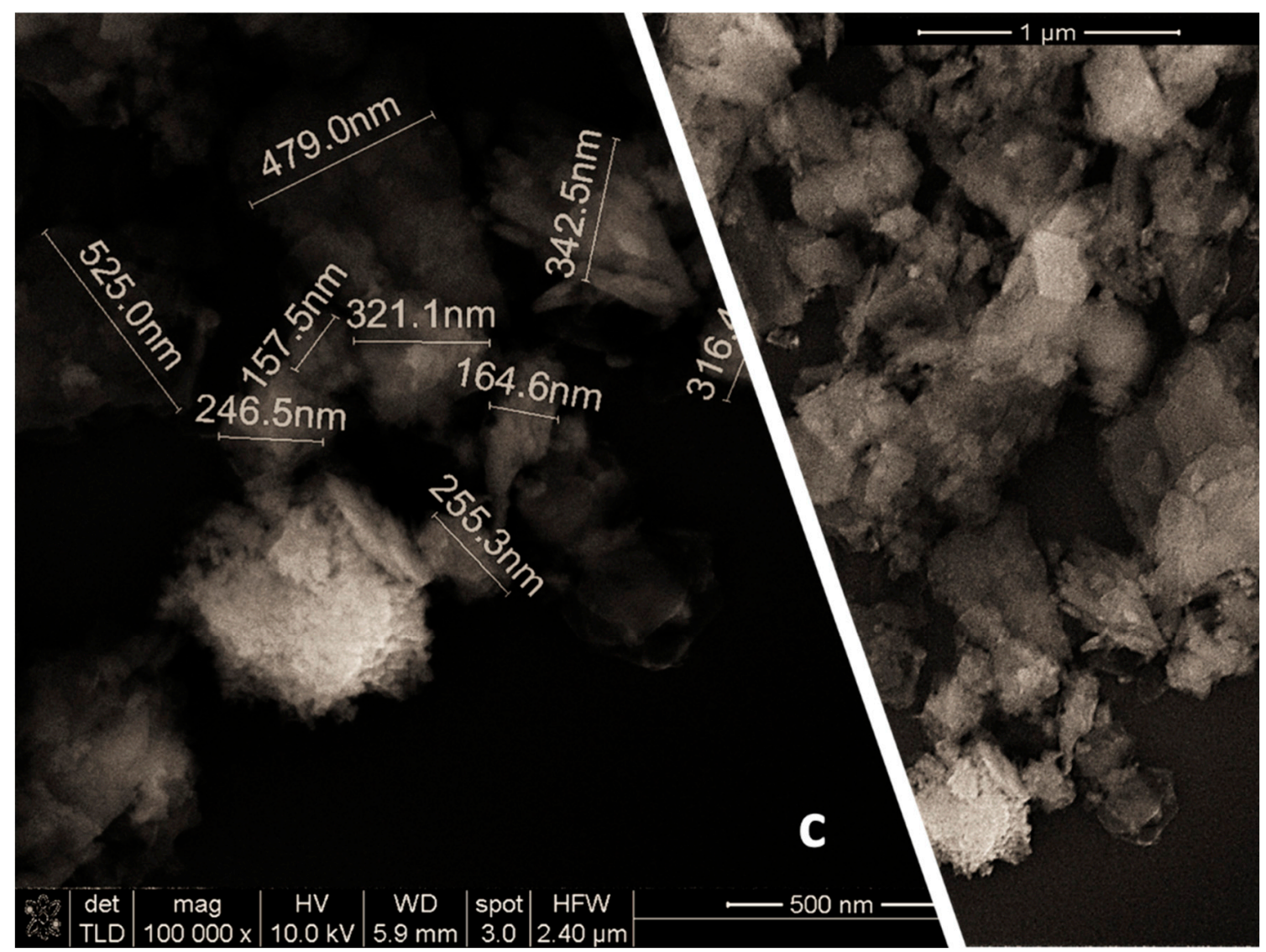

Figure 1. SEM images of the synthesized nanoparticles (a) $\mathrm{ZnO},(\mathbf{b}) \mathrm{TiO}_{2}$, and (c) zeolite.

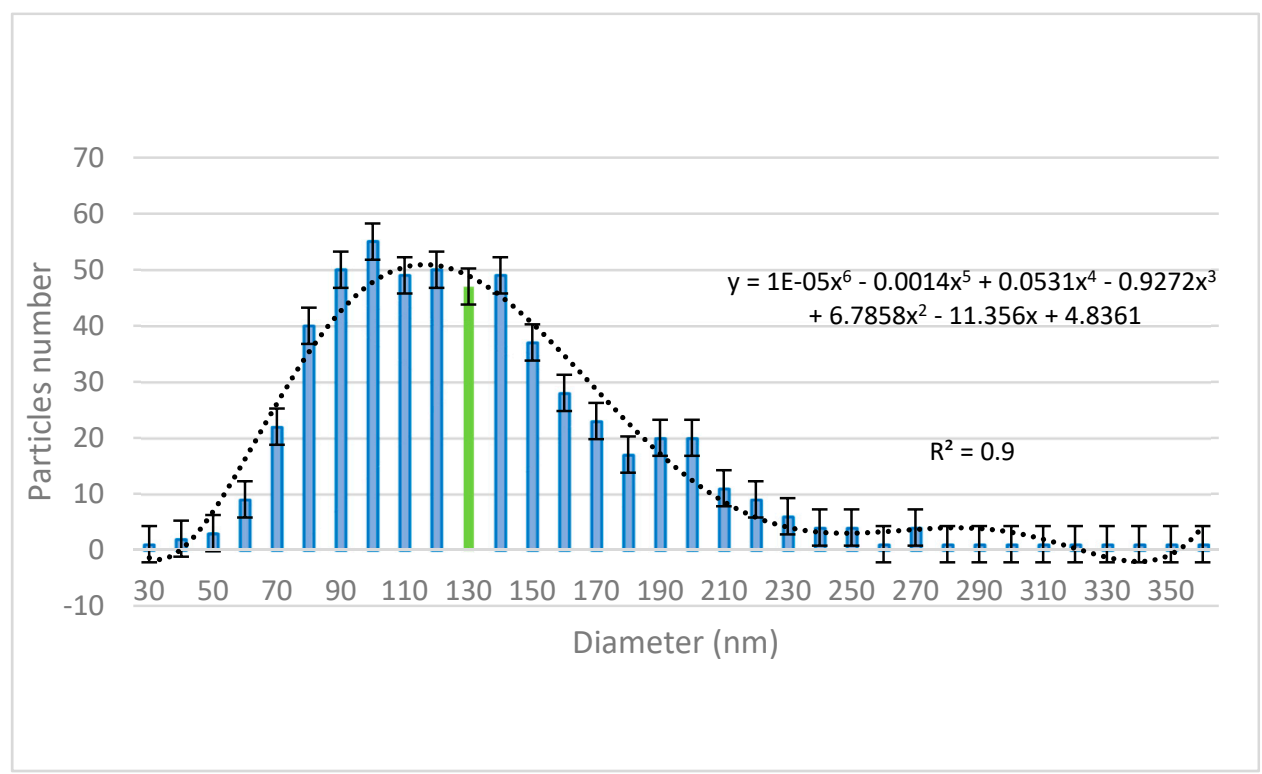

(a)

Figure 2. Cont. 


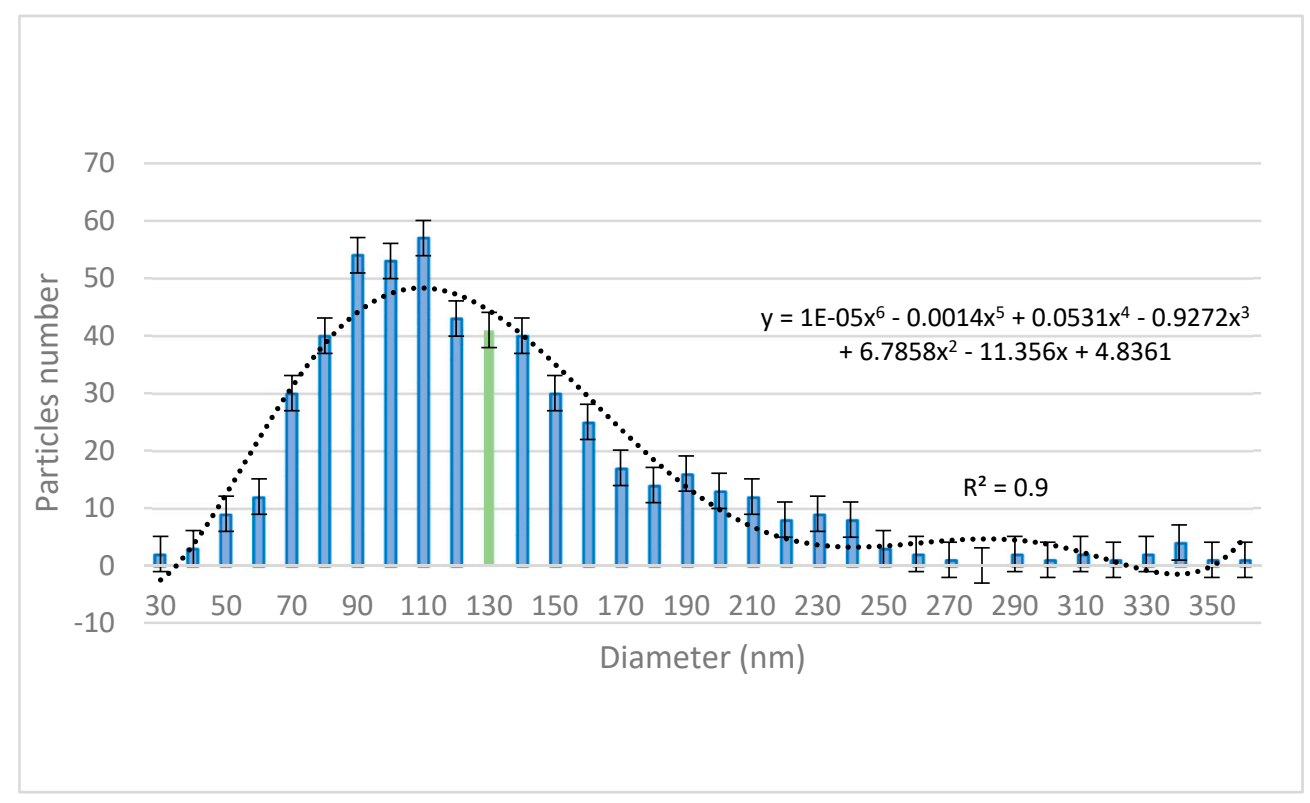

(b)

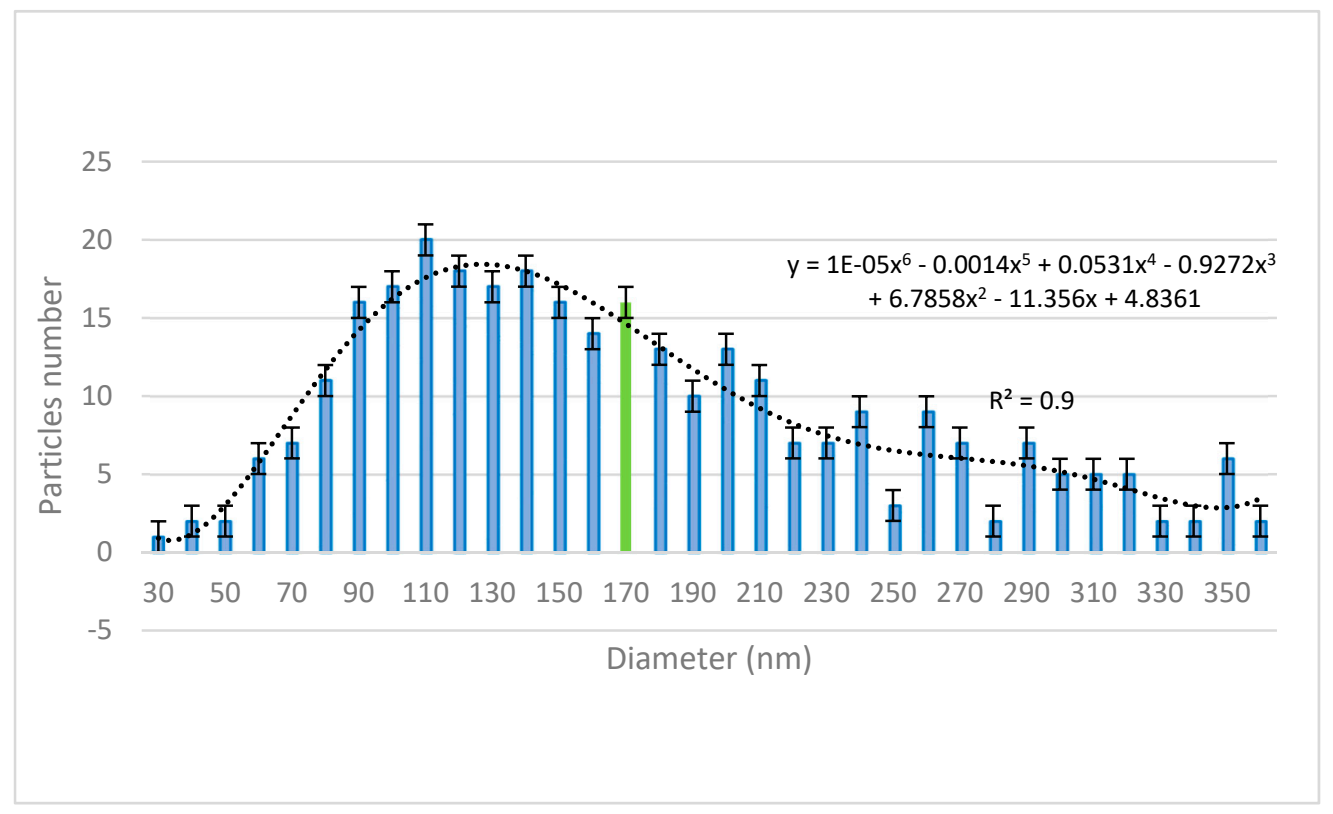

(c)

Figure 2. Size distribution of the synthesized nanoparticles: (a) $\mathrm{ZnO}$ (mean size value obtained: $134.2 \mathrm{~nm}$ ), (b) $\mathrm{TiO}_{2}$ (mean size value obtained: $131.2 \mathrm{~nm}$ ), and (c) zeolite (mean size value obtained: $171.1 \mathrm{~nm})$. 


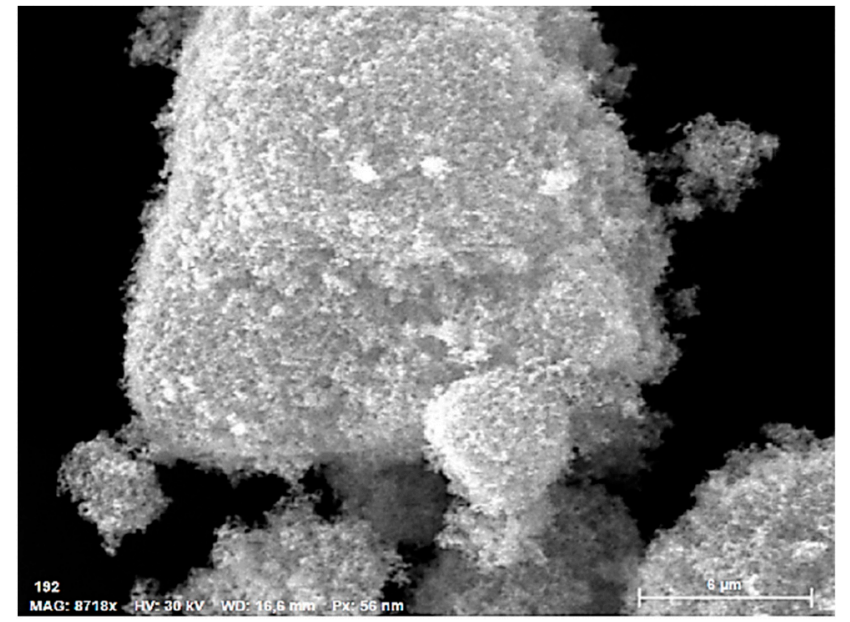

(a)

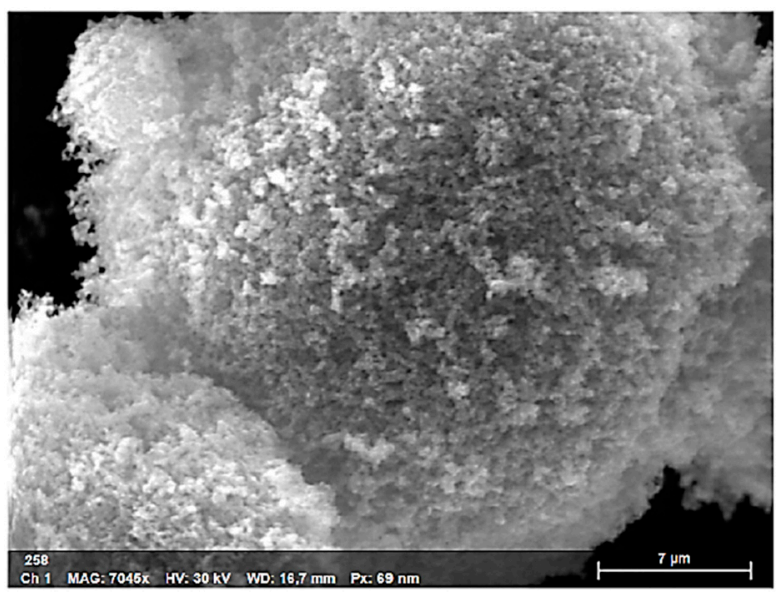

(c)

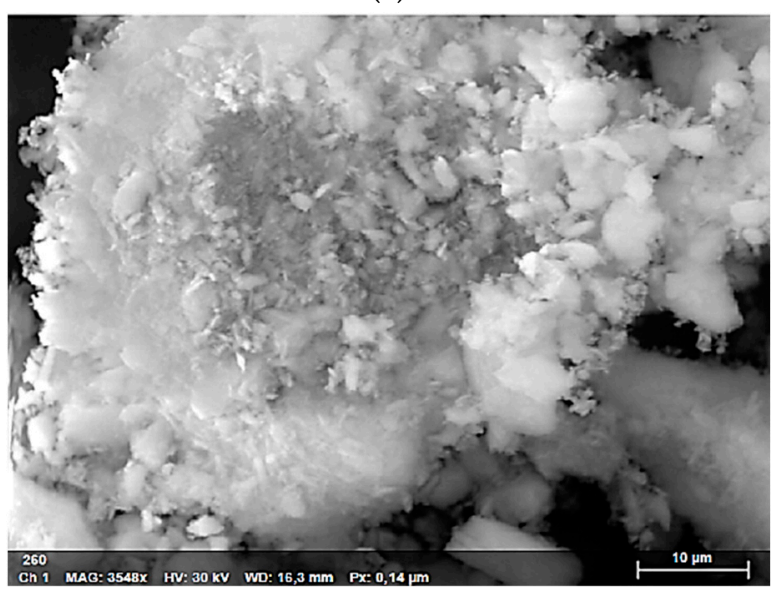

(e)

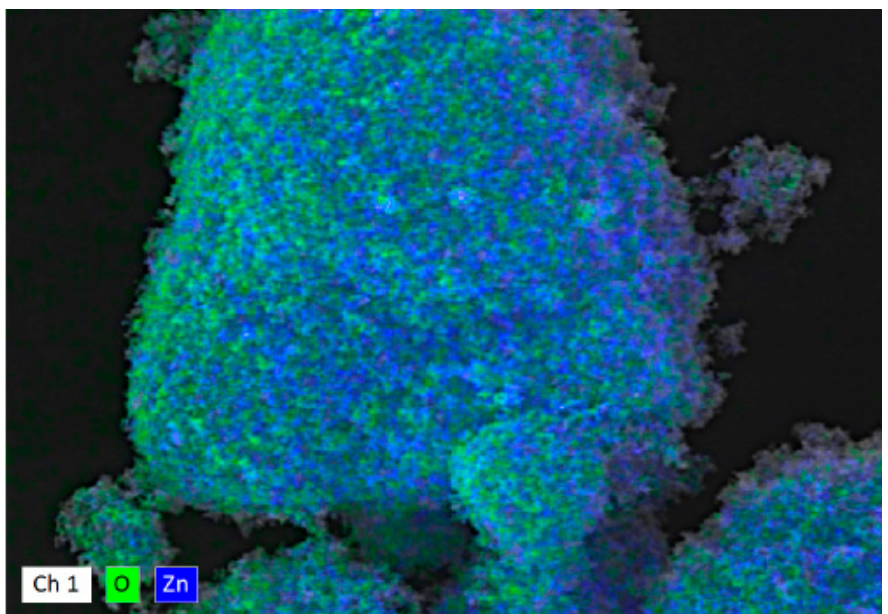

(b)

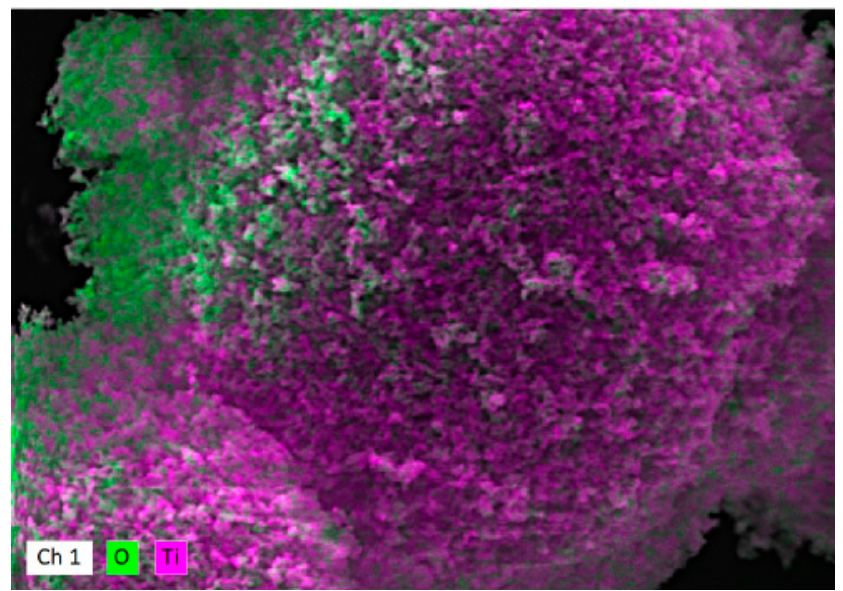

(d)

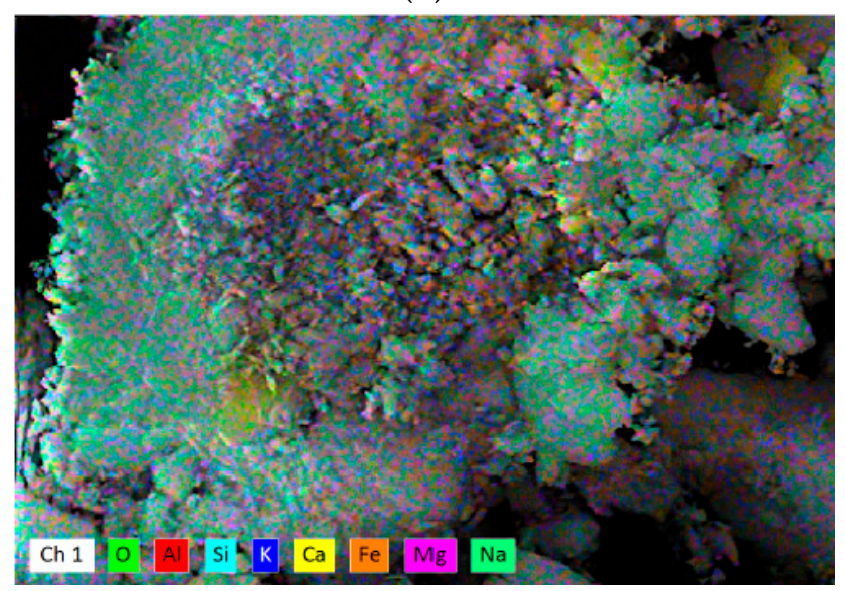

(f)

Figure 3. SEM and EDX mapping of nanoparticle clusters: $(\mathbf{a}, \mathbf{b}) \mathrm{ZnO},(\mathbf{c}, \mathbf{d}) \mathrm{TiO}_{2}$, and $(\mathbf{e}, \mathbf{f})$ zeolite. 


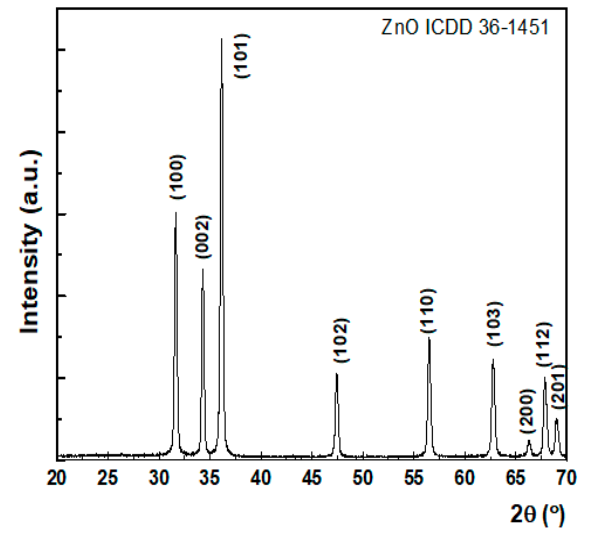

(a)

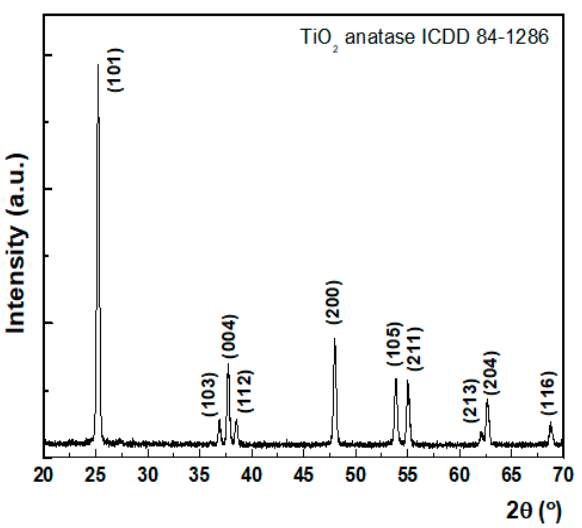

(b)

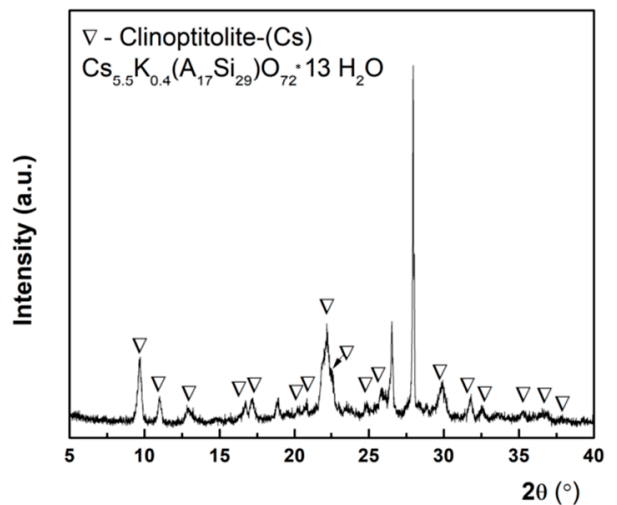

(c)

Figure 4. XRD patterns of the synthesized nanoparticles: (a) $\mathrm{ZnO},(\mathbf{b}) \mathrm{TiO}_{2}$, and (c) zeolite.

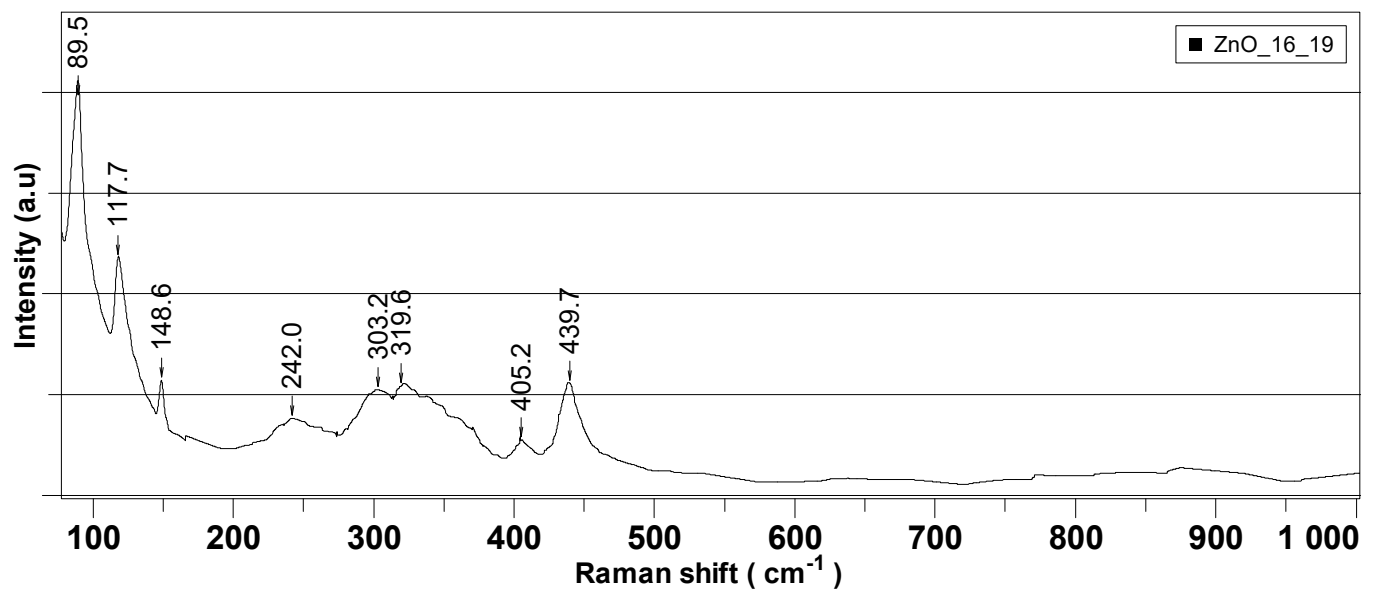

(a)

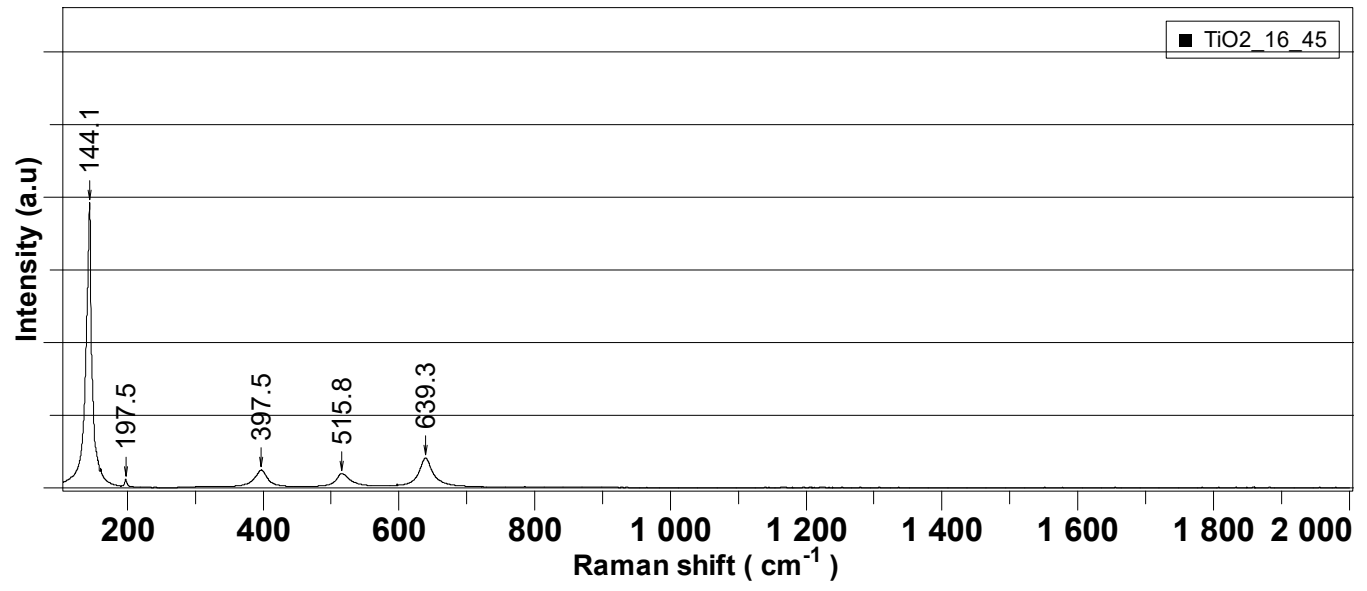

(b)

Figure 5. Cont. 


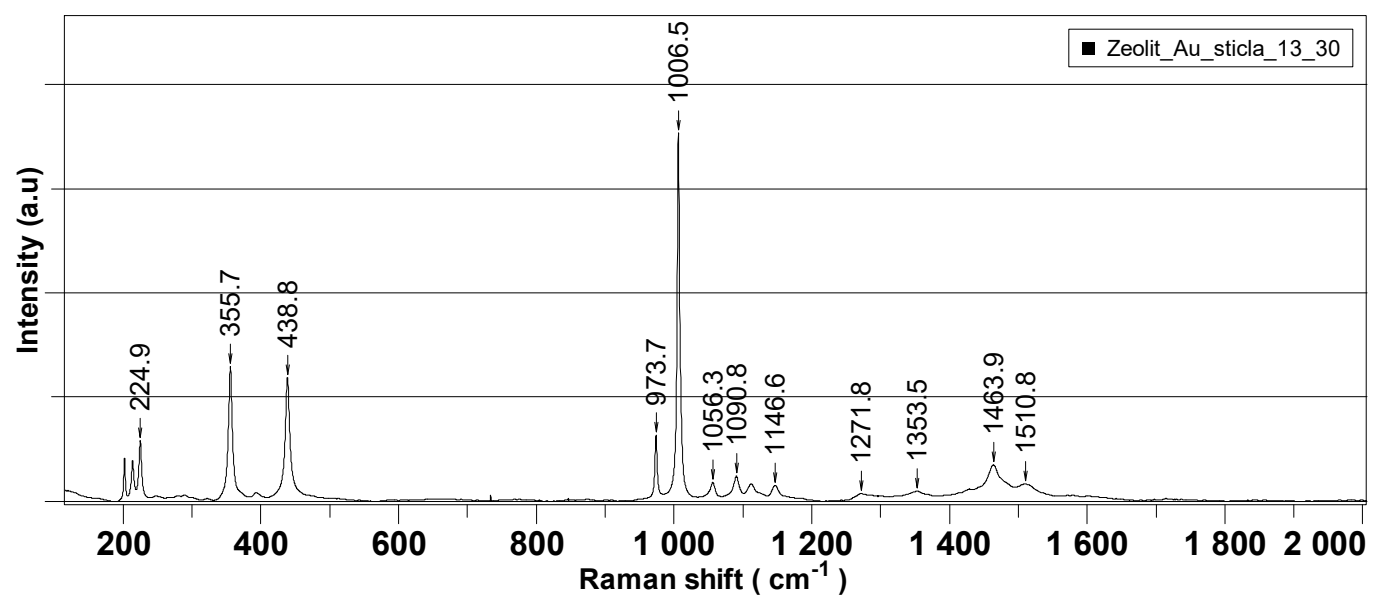

(c)

Figure 5. RAMAN spectra of the synthesized nanoparticles: (a) $\mathrm{ZnO}$, (b) $\mathrm{TiO}_{2}$, and (c) zeolite.

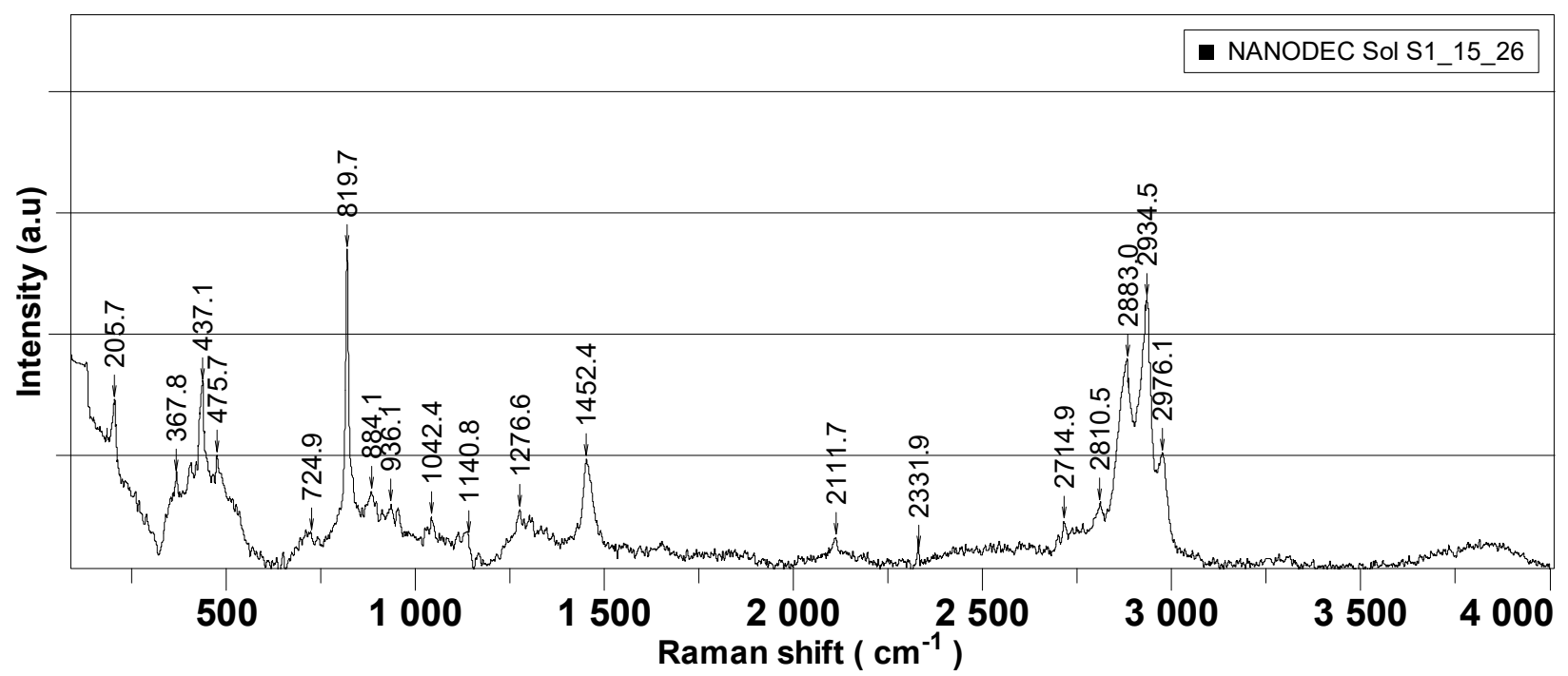

Figure 6. RAMAN spectra of the neat organic decontamination solution.

Table 2. Control $\ddagger$ of initial contamination level of the tested surfaces.

\begin{tabular}{|c|c|c|c|c|}
\hline Microorganism & $\begin{array}{l}\text { Painted Metal } \\
\left(\mathrm{CFU} / 10 \mathrm{~cm}^{2}\right) *\end{array}$ & $\begin{array}{c}\text { Glass } \\
\left(\mathrm{CFU} / 10 \mathrm{~cm}^{2}\right) *\end{array}$ & $\begin{array}{c}\text { Rubber } \\
\left(\mathrm{CFU} / 10 \mathrm{~cm}^{2}\right) *\end{array}$ & $\begin{array}{l}\text { Cotton Butyl Rubber } \\
\left(\text { CFU/10 } \mathrm{cm}^{2}\right)^{*}\end{array}$ \\
\hline Bacillus anthracis spores & TMTC ** & $25 \times 10^{3} \pm 458.25$ & $15 \times 10^{3} \pm 55.67$ & $30 \times 10^{3} \pm 55.67$ \\
\hline Bacillus cereus spores & $\mathrm{TMTC}^{* *}$ & $25 \times 10^{3} \pm 86.60$ & $31 \times 10^{3} \pm 100.00$ & $28 \times 10^{3} \pm 86.60$ \\
\hline Bacillus subtilis spores & $\mathrm{TMTC}^{* *}$ & $22 \times 10^{3} \pm 43.30$ & $27 \times 10^{3} \pm 91.65$ & $27 \times 10^{3} \pm 91.65$ \\
\hline Bacillus anthracis & $\mathrm{TMTC}^{* *}$ & $39 \times 10^{3} \pm 86.60$ & $26 \times 10^{3} \pm 43.30$ & $27 \times 10^{3} \pm 30.00$ \\
\hline Bacillus cereus & TMTC $^{* *}$ & $31 \times 10^{3} \pm 30.00$ & $25 \times 10^{3} \pm 100.00$ & $25 \times 10^{3} \pm 50.00$ \\
\hline Bacillus subtilis & $\mathrm{TMTC}^{* *}$ & $\mathrm{TMTC}^{* *}$ & $25 \times 10^{3} \pm 50.00$ & $19 \times 10^{3} \pm 55.67$ \\
\hline Staphylococcus aureus & $\mathrm{TMTC}^{* *}$ & $28 \times 10^{3} \pm 86.60$ & $16 \times 10^{3} \pm 124.90$ & $27 \times 10^{3} \pm 91.65$ \\
\hline Pseudomonas aeruginosa & TMTC $^{* *}$ & $\mathrm{TMTC}^{* *}$ & $22 \times 10^{3} \pm 30.00$ & $18 \times 10^{3} \pm 124.00$ \\
\hline
\end{tabular}

* The initial microbial load was $10^{4} \mathrm{CFU} / 10 \mathrm{~cm}^{2}$, both for spores and vegetative forms. $\ddagger$ Contamination control was performed by employing pre-moistened sterile swabs for sampling the microorganisms from the contaminated areas $\left(10 \mathrm{~cm}^{2}\right)$. The collected samples were allowed to grow on solid culture media. To verify contamination, colony-forming units were counted from the surface of the solid culture media. TMTC ${ }^{* *}=$ too many to count. Sample size (replicates) evaluated for each test was three. 
Table 3. Decontamination $\ddagger$ efficiency of the neat organic solution on various types of surfaces for different types of microorganisms.

\begin{tabular}{|c|c|c|c|c|}
\hline Microorganism & $\begin{array}{l}\text { Painted Metal } \\
\left(C F U / 10 \mathrm{~cm}^{2}\right) *\end{array}$ & $\begin{array}{c}\text { Glass } \\
\left(\mathrm{CFU} / 10 \mathrm{~cm}^{2}\right) *\end{array}$ & $\begin{array}{c}\text { Rubber } \\
\left(\mathrm{CFU} / 10 \mathrm{~cm}^{2}\right) *\end{array}$ & $\begin{array}{l}\text { Cotton Butyl Rubber } \\
\left(\text { CFU/10 } \mathrm{cm}^{2}\right) *\end{array}$ \\
\hline Bacillus anthracis spores & $<1$ & $<1$ & $2 \pm 1.00$ & $1 \pm 0.00$ \\
\hline Bacillus cereus spores & $3 \times 10^{2} \pm 2.65$ & $1.0 \times 10^{2} \pm 8.66$ & $1.1 \times 10^{2} \pm 8.66$ & $6 \times 10^{2} \pm 8.66$ \\
\hline Bacillus subtilis spores & $180 \pm 5.00$ & $2.0 \times 10^{2} \pm 8.66$ & $2.2 \times 10^{2} \pm 7.94$ & $160 \pm 2.00$ \\
\hline Bacillus anthracis & $<1$ & $<1$ & $<1$ & $<1$ \\
\hline Bacillus cereus & TMTC $^{* *}$ & $2.2 \pm 0.72$ & $3.0 \pm 1.00$ & $3.5 \pm 0.50$ \\
\hline Bacillus subtilis & TMTC ** & $10 \pm 2.65$ & $1.7 \pm 0.26$ & $2.1 \pm 0.17$ \\
\hline Staphylococcus aureus & $1.7 \pm 0.26$ & $4 \pm 0.00$ & $1.1 \pm 0.17$ & $2 \pm 1.00$ \\
\hline Pseudomonas aeruginosa & TMTC $^{* *}$ & $3 \pm 1.73$ & $2 \pm 1.00$ & $1 \pm 0.00$ \\
\hline
\end{tabular}

* Values obtained at the completion of the decontamination step (after 10 min of contact with the neat organic decontamination solution). $¥$ Decontamination control was performed by employing pre-moistened sterile swabs for sampling the microorganisms from the decontaminated areas $\left(10 \mathrm{~cm}^{2}\right)$. The collected samples were allowed to grow on solid culture media. To verify decontamination efficiency, colony-forming units were counted from the surface of the solid culture media. TMTC ${ }^{* *}=$ too many to count. Sample size (replicates) evaluated for each test was three.

After the evaluation of the neat organic solutions, the NPs-enriched decontamination solutions were also subjected to analysis for establishing their influence on the biological decontamination capacity.

It is worth mentioning that the solutions comprising the nanoparticles were firstly subjected to the same procedures as the neat DS but we obtained almost similar results probably due to the particularities of each surface tested (porosity, rugosity, etc.), which have a major influence on the success of the decontamination process, and probably also due to the too low concentration of NPs employed for these tests. Thus, we can affirm that we were not able to prove the contribution of the NPs to the improvement of the decontamination efficiency of DS through the classical methods presented in NATO standards. Therefore, we employed other procedures for biological and chemical decontamination, which implied direct contact between the contaminants and the decontamination suspensions comprising the NPs, as further described.

Given the presence of nanoparticles in these new decontamination solutions (nanoparticles in suspension), other microbiology techniques, as detailed below, were better suited for the evaluation of their antimicrobial activity. Therefore, for this purpose, the minimal inhibitory concentration (MIC), minimal bactericidal concentration (MBC), and time-kill test methods were employed for comparing the decontamination performances of NPs ${ }^{\prime}$ suspensions (Table 4).

Table 4. Minimal inhibitory concentration (MIC) and minimal bactericidal concentration (MBC) values.

\begin{tabular}{|c|c|c|c|c|c|c|c|c|}
\hline \multirow[b]{2}{*}{ Sample/Microorganism } & \multicolumn{2}{|c|}{ E. coli } & \multicolumn{2}{|c|}{ Ps. aeruginosa } & \multicolumn{2}{|c|}{ S. aureus } & \multicolumn{2}{|c|}{ B. spizizenii } \\
\hline & $\begin{array}{c}\text { MIC } \\
(\%)\end{array}$ & $\begin{array}{c}\text { MBC } \\
(\%)\end{array}$ & $\begin{array}{c}\text { MIC } \\
(\%)\end{array}$ & $\begin{array}{c}\text { MBC } \\
(\%)\end{array}$ & $\begin{array}{c}\text { MIC } \\
(\%)\end{array}$ & $\begin{array}{c}\text { MBC } \\
(\%)\end{array}$ & $\begin{array}{c}\text { MIC } \\
(\%)\end{array}$ & $\begin{array}{c}\text { MBC } \\
(\%)\end{array}$ \\
\hline DS & 0.0159 & 0.0625 & 0.008 & 0.25 & 0.008 & 0.0159 & 0.004 & 0.0159 \\
\hline DS-ZnO-0.5 & 0.0159 & 0.0625 & 0.008 & 0.25 & 0.008 & 0.031 & 0.004 & 0.031 \\
\hline DS-ZnO-1 & 0.008 & 0.0625 & 0.008 & 0.0625 & 0.004 & 0.0625 & 0.004 & 0.031 \\
\hline DS- $\mathrm{TiO}_{2}-0.5$ & 0.0159 & 0.0625 & 0.008 & 0.25 & 0.008 & 0.0625 & 0.008 & 0.031 \\
\hline DS- $\mathrm{TiO}_{2}-1$ & 0.0159 & 0.125 & 0.008 & 0.031 & 0.008 & 0.0625 & 0.008 & 0.031 \\
\hline DS-Z-0.5 & 0.008 & 0.25 & 0.008 & 0.031 & 0.008 & 0.0625 & 0.004 & 0.031 \\
\hline DS-Z-1 & 0.008 & 0.0625 & 0.008 & 0.0159 & 0.008 & 0.0159 & 0.004 & 0.031 \\
\hline
\end{tabular}

Taking into account that the results were identical between replicates, we did not display the standard deviation that is \pm 0 .

The time kill assay (Figure S3-Supplementary Material File) was performed only on E. coli and S. aureus, and the suspensions used to perform the tests were $2 \times 10^{7} \mathrm{CFU} / \mathrm{mL}$ 
for $E$. coli and $6 \times 10^{7} \mathrm{CFU} / \mathrm{mL}$ for $S$. aureus. The plates inoculated after $3 \mathrm{~h}$ of contact had sporadic growth for the DS- $\mathrm{ZnO}-0.5$ and DS- $\mathrm{ZnO}-1$ samples on each microorganism. After $6 \mathrm{~h}$ of contact, no signs of growth were observed for any microorganism. The number of CFU recovered after the incubation time were between 1 and 15 CFU/MHa plate for Ecoli and between 3 and $25 \mathrm{CFU} / \mathrm{MHa}$ plate for S. aureus. The results were, even between replicates, very different. Unfortunately, the low level of CFU/agar plates (maximum $25 \mathrm{CFU}$ / plate) and the differences between replicates make these results unreliable for a statistical interpretation [36].

In parallel, an extensive evaluation of the decontamination efficacy for two real chemical warfare agents (yperite and soman) was performed, utilizing the neat organic solution along with the decontamination solutions enriched with the nanosized adsorbents. Prior to the dispersion of the nano adsorbents in the organic solution, the neat decontamination solution (sample DS, Table 1) was tested against chemical warfare agents (described in detail in the Methods section) before and after being subjected to various temperature cycles. These tests had the purpose of demonstrating that neat DS maintains its decontamination performances even after being subjected to extreme environmental conditions (Figure 7), this being an important feature for the formulations employed in military operational scenarios. The decontamination capacity of neat DS against sulfur mustard (HD) and soman (GD) on different types of surfaces was evaluated and the results are detailed in Table 5 while the remnant toxic concentrations are depicted in Figure 8.
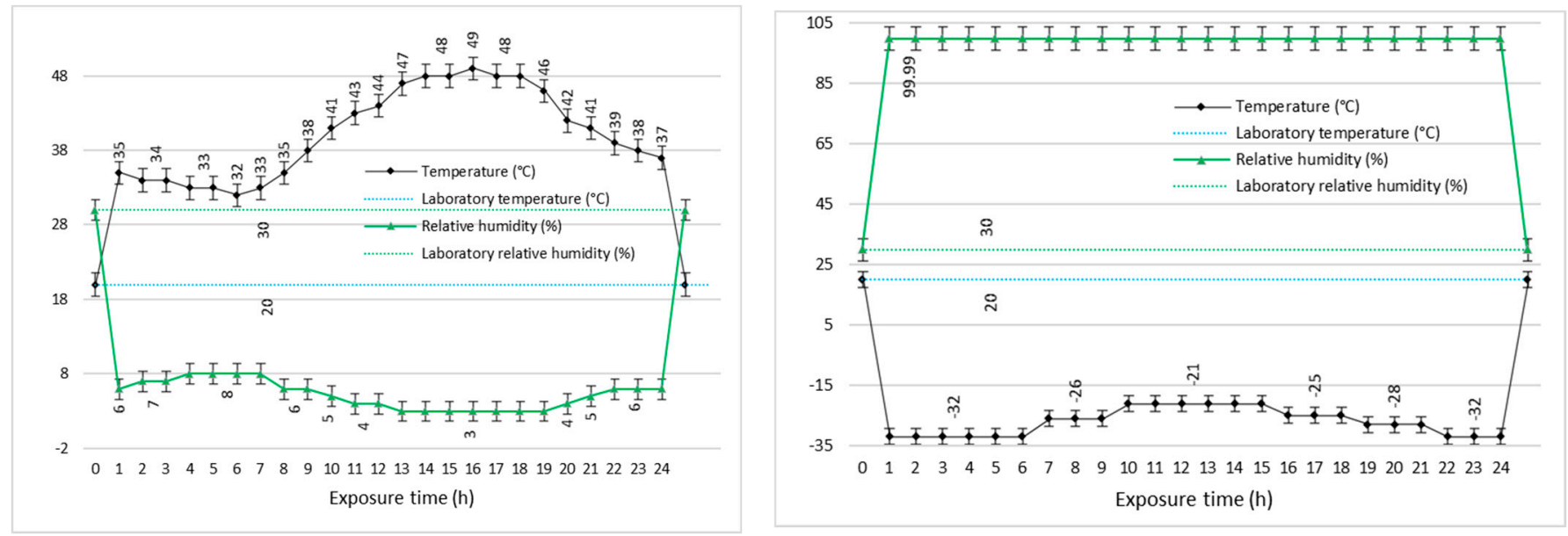

Figure 7. Temperature cycles assay on neat DS.

Table 5. Decontamination efficiency of neat DS on sulfur mustard (HD) and soman (GD).

\begin{tabular}{|c|c|c|c|c|c|c|}
\hline \multirow{4}{*}{ Surface Tested } & \multicolumn{3}{|c|}{ HD Decontamination Efficiency (\%) } & \multicolumn{3}{|c|}{ GD Decontamination Efficiency (\%) } \\
\hline & \multirow{3}{*}{ DS } & DS After & \multirow{3}{*}{$\begin{array}{c}\text { DS After } \\
\text { C1 Cycle } \\
\left(20 \ldots-33^{\circ} \mathrm{C}\right)\end{array}$} & \multirow{3}{*}{ DS } & \multirow{2}{*}{$\begin{array}{l}\text { DS After } \\
\text { A1 Cycle }\end{array}$} & \multirow{2}{*}{$\begin{array}{l}\text { DS After } \\
\text { C1 Cycle }\end{array}$} \\
\hline & & A1 Cycle & & & & \\
\hline & & $\left(20 \ldots 49{ }^{\circ} \mathrm{C}\right)$ & & & $\left(20 \ldots 49^{\circ} \mathrm{C}\right)$ & $\left(20 \ldots-33^{\circ} \mathrm{C}\right)$ \\
\hline Painted metal & $99.40 \pm 0.34$ & $99.20 \pm 0.45$ & $99.30 \pm 0.41$ & $99.99 \pm 0.00$ & $99.99 \pm 0.00$ & $99.99 \pm 0.00$ \\
\hline Rubber & $99.20 \pm 0.08$ & $99.10 \pm 0.78$ & $99.10 \pm 0.03$ & $99.98+0.08$ & $99.95 \pm 0.34$ & $99.98 \pm 0.01$ \\
\hline Glass & $99.98 \pm 0.40$ & $100.00 \pm 0.00$ & $99.97+0.00$ & $100.00 \pm 0.00$ & $99.99+0.00$ & $100.00 \pm 0.00$ \\
\hline Cotton butyl rubber & $99.40 \pm 0.53$ & $99.30 \pm 0.52$ & $99.40 \pm 0.23$ & $99.93 \pm 0.03$ & $99.93 \pm 0.07$ & $99.93 \pm 0.11$ \\
\hline Minimum allowable efficiency * & $99.00 \pm 0.86$ & $99.00+0.76$ & $99.00 \pm 0.74$ & $99.90 \pm 0.04$ & 99.90 & $99.90 \pm 0.04$ \\
\hline $\begin{array}{l}\text { Sample size (replicates) } \\
\text { evaluated for each surface }\end{array}$ & 3 & 3 & 3 & 3 & 3 & 3 \\
\hline
\end{tabular}

* according to NATO standard [37]. 


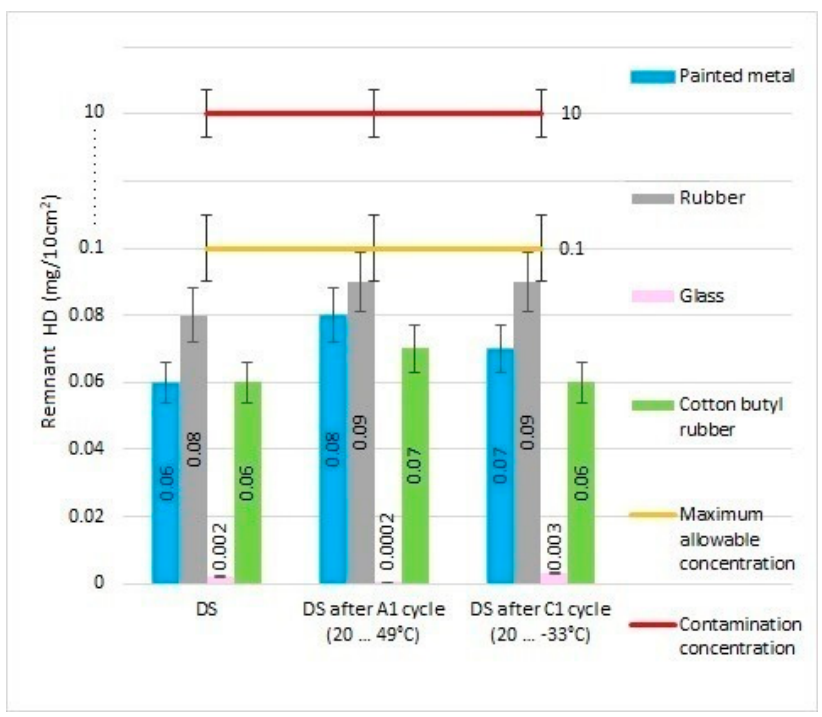

(a)

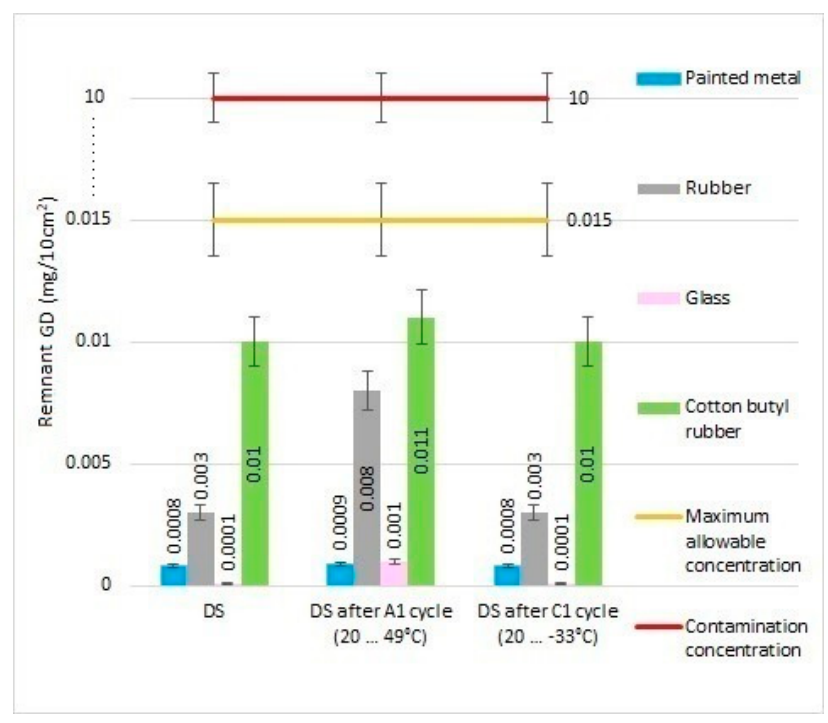

(b)

Figure 8. Remnant toxic concentrations (a) HD and (b) GD after decontamination with neat DS on different types of surfaces.

The last step consisted of the evaluation of the decontamination efficacy of the NPsbased decontamination solutions against HD and GD. The decontamination degrees obtained for decontamination formulations and the remnant toxic concentrations are summarized in Figures 9-12. For all these experiments, the decontamination efficiency was calculated according to the formula described in the Methods Section, $\mathrm{DF}=100 \cdot\left(\mathrm{C}_{0}-\mathrm{C}_{\mathrm{f}}\right) / \mathrm{C}_{0}$, thus the values obtained for the decontamination factor (DF) are all displayed in these figures in percentage units (\%). DF represents the difference calculated between the initial concentration (time 0 ) and the concentration measured at a specific moment relative to the initial contamination (at time $0 \mathrm{~min}$ ).

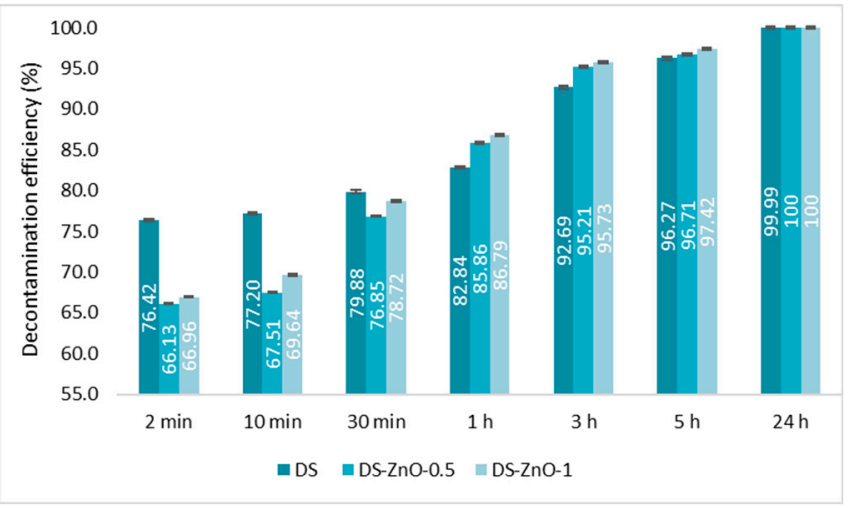

(a)

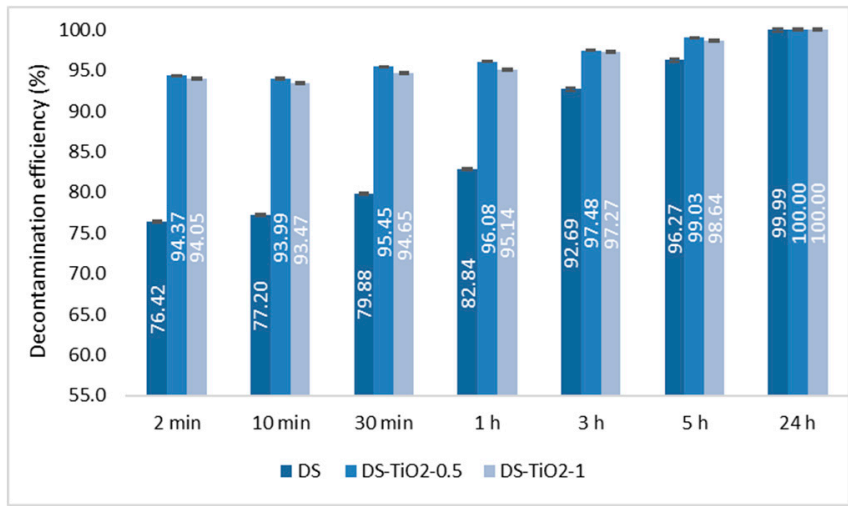

(b)

Figure 9. Cont. 


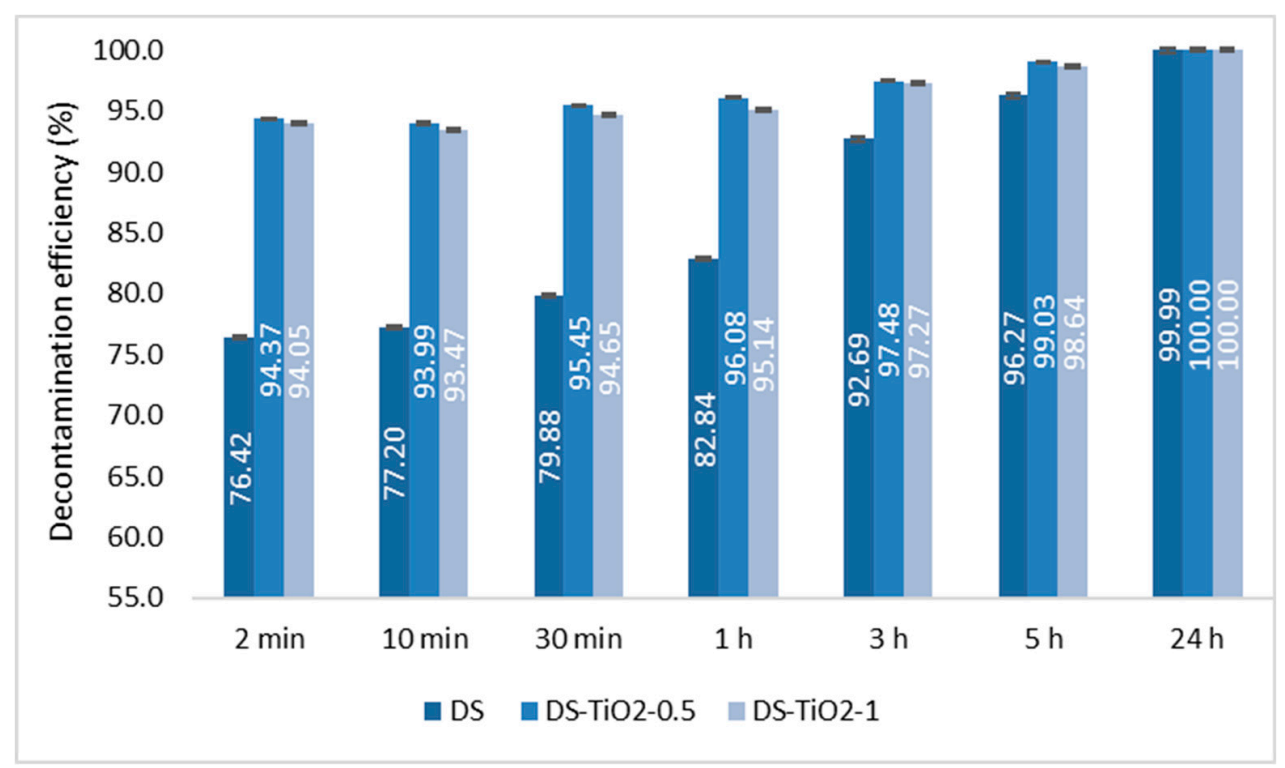

(c)

Figure 9. Decontamination degrees (\%) of sulfur mustard (HD) obtained for decontamination formulations containing: (a) $\mathrm{ZnO},(\mathbf{b}) \mathrm{TiO}_{2}$, and (c) zeolite (detailed statistical data presented in Tables S9 and S10-Supplementary Material File).

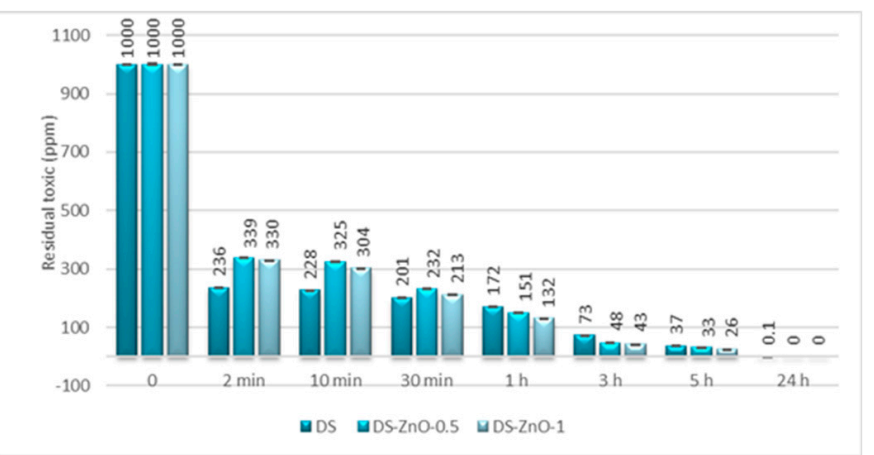

(a)

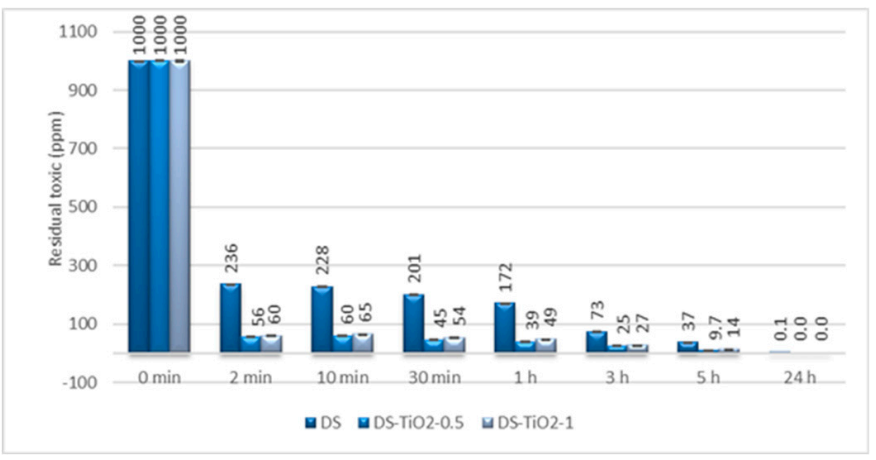

(b)

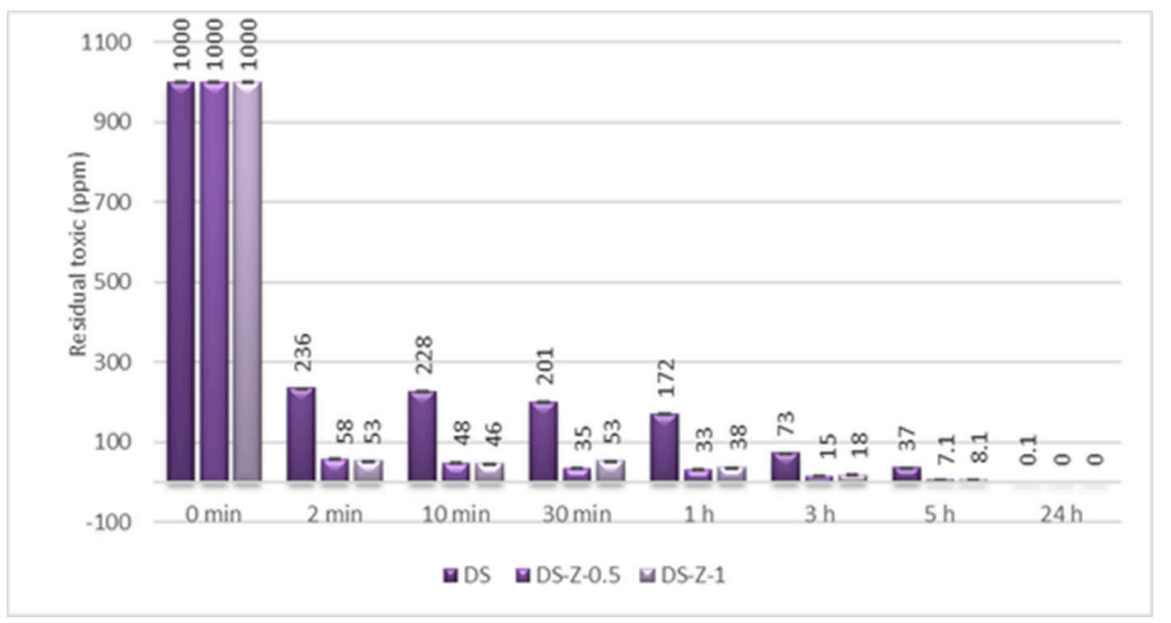

(c)

Figure 10. Residual sulfur mustard after employing decontamination formulations based on (a) $\mathrm{ZnO}$, (b) $\mathrm{TiO}_{2}$, and (c) zeolite (detailed statistical data presented in Tables S9 and S10-Supplementary Material File). 


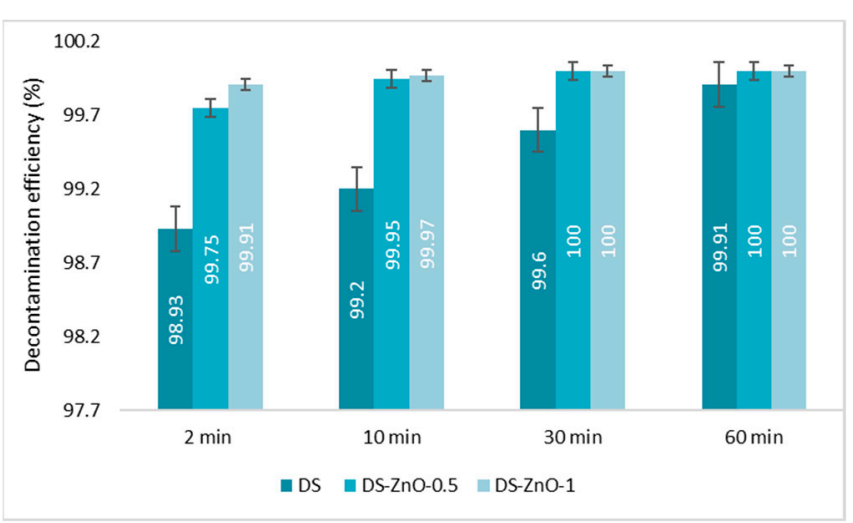

(a)

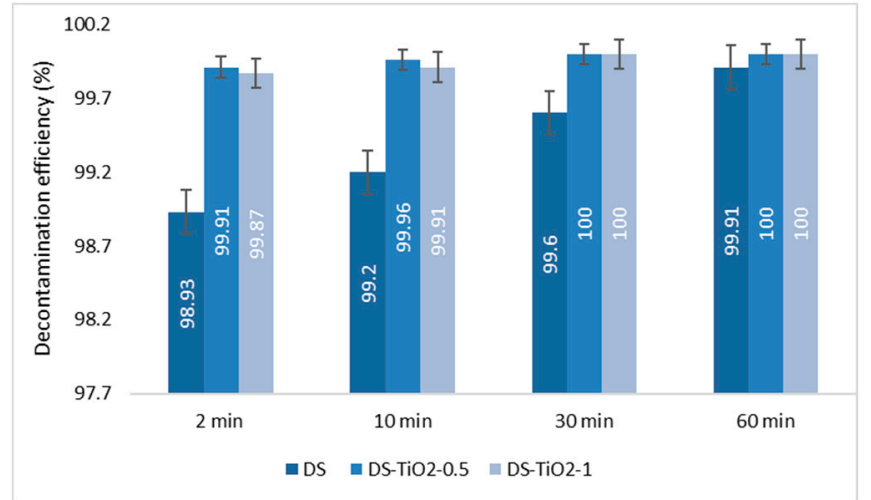

(b)

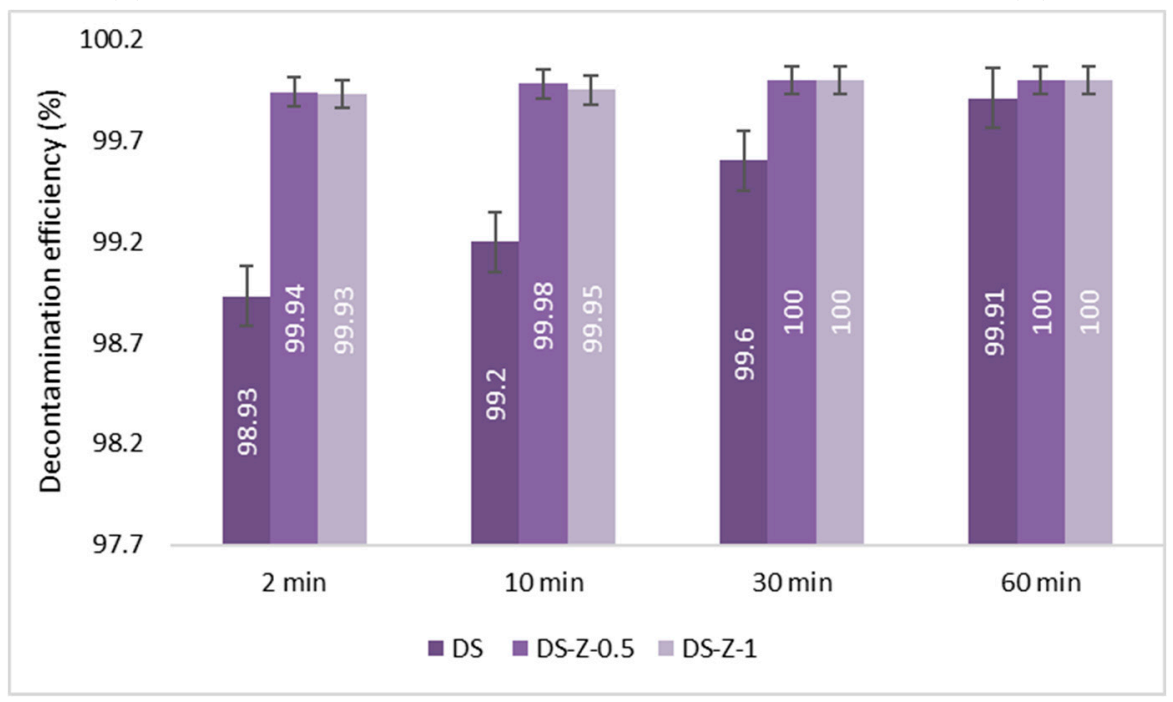

(c)

Figure 11. Decontamination degrees (\%) of soman (GD) obtained for decontamination formulations containing: (a) $\mathrm{ZnO}$, (b) $\mathrm{TiO}_{2}$, and (c) zeolite (detailed statistical data presented in Tables S9 and S10Supplementary Material File).

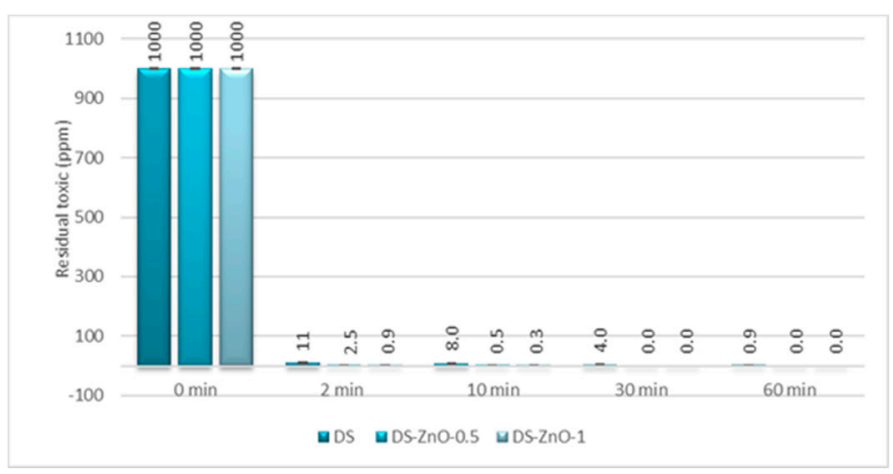

(a)

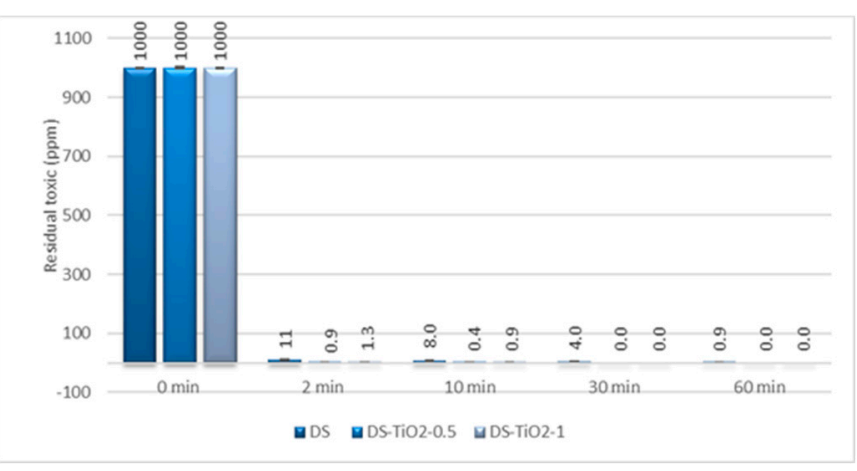

(b)

Figure 12. Cont. 


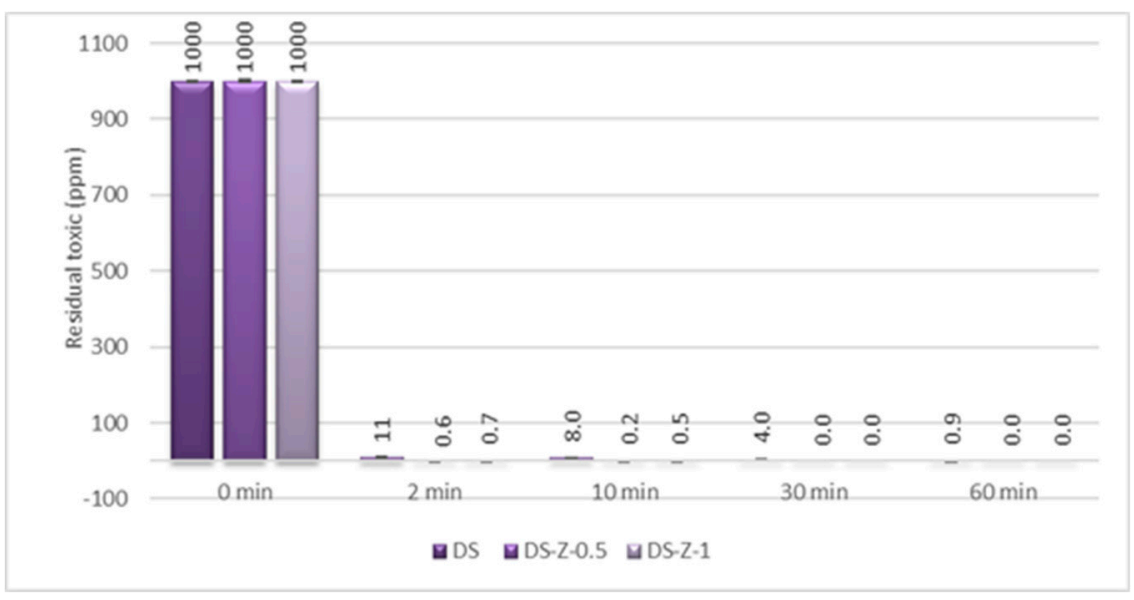

(c)

Figure 12. Residual soman after employing decontamination formulations based on (a) $\mathrm{ZnO}$, (b) $\mathrm{TiO}_{2}$, and (c) zeolite (detailed statistical data presented in Tables S9 and S10-Supplementary Material File).

\section{Discussion}

The present work is comprised of a decontamination study on real and simulated biological and chemical warfare agents, in which the focus was on evaluating the antimicrobial activity and capacity of neutralizing the chemical warfare agents of three different types of organic solutions enriched with $\mathrm{ZnO}, \mathrm{TiO}_{2}$, and zeolite nanoparticles specially designed for decontamination applications. The first step of this study consisted of the synthesis of the nanoparticles, followed by the development of the decontamination suspensions. The synthesis of $\mathrm{ZnO}$ nanoparticles, as detailed in the Methods section below, led to round-shaped nanoparticles (Figure 1a) with dimensions ranging in the 50-230 nm interval. These nanoparticles were further employed for obtaining the decontamination suspensions DS-ZnO-0.5 (containing 0.5 wt. \% ZnO NPs) and DS-ZnO-1 (containing $1 \mathrm{wt}$ \% ZnO NPs). The morphology of $\mathrm{TiO}_{2}$ nanoparticles was similar with the one of $\mathrm{ZnO}$ nanoparticles. Round-shaped $\mathrm{TiO}_{2}$ (Figure $1 \mathrm{~b}$ ) nanoparticles, most of them measuring between 50 and $210 \mathrm{~nm}$, were employed for the synthesis of the $\mathrm{DS}_{-} \mathrm{TiO}_{2}-0.5$ (containing $0.5 \mathrm{wt}$. $\% \mathrm{TiO}_{2} \mathrm{NPs}$ ) and DS- $\mathrm{TiO}_{2}-1$ decontamination suspensions (containing $1 \% \mathrm{TiO}_{2} \mathrm{NPs}$ ). The micronized zeolite clinoptilolite (MZC) was subjected to ultrasonication in isopropyl alcohol prior to its addition in the decontamination solution in order to reduce the size of the particles for ensuring a higher active specific surface. SEM images (Figure 1c) revealed the morphology of the zeolite nanoparticles obtained through the above-mentioned procedure. As can be observed, zeolite particles do not possess a regular shape, with both isolated nanoparticles (ranging from 50 to $350 \mathrm{~nm}$, Figure 2c) and mesoporous aggregates being present. Even if the dimensions of zeolite nanoparticles were higher than the ones of $\mathrm{ZnO}$ and $\mathrm{TiO}_{2}$, their high porosity ensured an efficient decontamination capacity of the suspensions in which they were employed, namely DS-Z-0.5 (containing $0.5 \%$ zeolite NPs) and DS-Z-1 (containing $1 \mathrm{wt}$. \% zeolite NPs). SEM-EDX investigations revealed the proportions of particle clusters (associations), their morphology, and also their composition. EDX mapping (Figure $3 \mathrm{~d}-\mathrm{f}$ ) offered evidence on the distribution of each identified element and also on their relative abundance. As can be observed in Figure 3, in comparison with $\mathrm{ZnO}$ and $\mathrm{TiO}_{2}$, which displayed a homogeneous distribution of the constituent elements, the atoms identified in the zeolite displayed a disparate distribution.

Powder X-ray diffraction investigations were performed on all the three types of nanosized adsorbents which were further introduced in the decontamination formulations. Thus, PXRD patterns of the investigated materials, namely (a) $\mathrm{ZnO}$, (b) $\mathrm{TiO}_{2}$, (c) zeolite, can be examined from Figure 4 . As can be observed, each pattern presents multiple diffraction peaks further assigned according to the ICDD (International Centre for Diffraction Data) database. The XRD pattern for $\mathrm{ZnO}$ powder, as shown in Figure 4a, showed the presence of 
pure wurtzite $\mathrm{ZnO}$ with the crystalline lattice constant, namely $\mathrm{a}=\mathrm{b}=3.25 \AA$ and $\mathrm{c}=5.22 \AA$, belonging to the P63 $(\mathrm{mc})$ space group, in accordance with the standard database (JCPDS file 36-1451). The mean crystallite size was evaluated as $33.1 \mathrm{~nm}$ (Scherrer equation [38]) and with a tensile lattice strain of $0.12 \%$. No peaks corresponding to impurities were detected, showing that the final synthesis products purely consist of $\mathrm{ZnO}$. Similarly, for $\mathrm{TiO}_{2}$ powder, the presence of pure anatase phase was shown with lattice constants $a=b=0.37 \mathrm{~nm}$ and $\mathrm{c}=0.95 \mathrm{~nm}$, belonging to the I41/amd tetragonal space group, consistent with the standard database (JCPDS file 84-1286). The mean crystallite size was evaluated as $32 \mathrm{~nm}$ (Scherrer equation) and with a tensile lattice strain of $0.10 \%$. No peaks corresponding to impurities were detected, showing that the final products purely consist of $\mathrm{TiO}_{2}$ anatase phase. In the case of zeolite, it seems that a phase combination is involved. As it resulted from the XRD spectra after phase identification, it belongs to the heulandite group, which may include several clinoptilolite specimens. Regarding the investigated zeolite, specifically clinoptilolite $\left(\mathrm{Cs}_{5.5} \mathrm{~K}_{0.4}\left(\mathrm{Al}_{7} \mathrm{Si}_{29}\right) \mathrm{O}_{72} \mathrm{H}_{2} \mathrm{O}\right)$, used in this paper, it seems that a phase combination is involved. According to the phase identification, clinoptitolite $\left(\mathrm{Cs}_{5.5} \mathrm{~K}_{0.4}\left(\mathrm{Al}_{7} \mathrm{Si}_{29}\right)\right.$ $\mathrm{O}_{72} \mathrm{H}_{2} \mathrm{O}$ ) was found alongside the monoclinic phase with $\mathrm{a}=1.77 \mathrm{~nm}, \mathrm{~b}=1.79 \mathrm{~nm}$, and $\mathrm{c}=0.74 \mathrm{~nm}$, while the angles had the following values: $\alpha=90^{\circ}, \beta=116.18^{\circ}$, and $\gamma=90^{\circ}$. The unidentified diffraction peaks might be assigned to laumontite monoclinic phase $\left(\mathrm{Ca}_{7}\right.$ $\left.\mathrm{Al}_{14} \mathrm{Si}_{26} \mathrm{O}\right)$ or muscovite $\left(\mathrm{H}_{2} \mathrm{~K} \mathrm{Al}_{3} \mathrm{Si}_{3} \mathrm{O}_{12}\right)$. The good crystalline quality in each case is confirmed by the mean crystallite sizes above $20 \mathrm{~nm}$ according to Scherrer's equation [38].

Raman analysis was performed separately on nanoparticles' powders and on the neat DS, and the results are illustrated in Figures 5 and 6, respectively. The properties of nanosized materials are strongly related to their structure; therefore, the structure of the synthesized nanoparticles was studied to understand the structure-property relationships in correlation with the application for which the nanoparticles were designed for. Raman spectra provided supplementary information about the crystalline structure of the investigated samples. According to the group theory, the wurtzite $\mathrm{ZnO}$ single-crystal belonging to the $46 \mathrm{v} \mathrm{C}(\mathrm{P} 63 \mathrm{mc})$ space group has 1A1, 2B1, 1E1, and 2E2 optical phonon modes $[39,40]$. The non-polar phonon mode, namely E2, had two frequencies: the E2 (low) and E2 (high) modes, which are associated with the non-polar vibration of the heavier $\mathrm{Zn}$ atoms sublattice and of the lighter oxygen atoms sublattice, respectively. Figure 2 shows the Raman spectra in the range of $70-1000 \mathrm{~cm}^{-1}$ for the prepared $\mathrm{ZnO}$ nanoparticles. The Raman spectra of all the samples exhibited the E2 (high) and E2 (low) modes at $\sim 439.6 \mathrm{~cm}^{-1}$ and $\sim 89.4 \mathrm{~cm}^{-1}$, respectively, demonstrating that ZnO-prepared NPs' structures are of wurtzite hexagonal phase. The peaks corresponding to E2 (high) and E2 (low) have a reasonable line width of about $15 \mathrm{~cm}^{-1}$ for all the measured samples and no broad Raman signal in the range of $500-1000 \mathrm{~cm}^{-1}$ was found, which confirms the crystal quality of the prepared nanoparticles. At the same time, the peaks corresponding to the E2 (high) mode are red-shifted for all the samples from $\sim 439.6 \mathrm{~cm}^{-1}\left(437 \mathrm{~cm}^{-1}\right.$ for ZnO bulk crystal) most likely due to the presence of some impurities (less than $0.5 \%$ ) and/or a small strain in the structures. These Raman shifts of the main peaks existing in the Raman spectra of ZnO NPs are generally characteristic for $\mathrm{ZnO}$-prepared/synthesized nanostructures, with different morphologies and defects. Titanium dioxide $\left(\mathrm{TiO}_{2}\right)$ is a polymorphic material occurring in three naturally crystalline phases: anatase, rutile, and brookite [41]. $\mathrm{TiO}_{2}$ is also an environmentally friendly material with various contents of these polymorphs, which have been attracting great interest because of their mechanical, electrical, optical, biological, and magnetic properties [42]. Anatase phase is tetragonal, with two formula units per unit cell, and has six Raman active modes (A1g, 2B1g, and 3Eg); these Raman vibrational modes are centered at $144 \mathrm{~cm}^{-1}\left(\mathrm{E}_{\mathrm{g}}\right), 197 \mathrm{~cm}^{-1}\left(\mathrm{E}_{\mathrm{g}}\right), 399 \mathrm{~cm}^{-1}\left(\mathrm{~B} 1_{\mathrm{g}}\right), 513 \mathrm{~cm}^{-1}\left(\mathrm{~A} 1_{\mathrm{g}}\right), 519 \mathrm{~cm}^{-1}\left(\mathrm{~B} 1_{\mathrm{g}}\right)$, and $639 \mathrm{~cm}^{-1}\left(\mathrm{E}_{\mathrm{g}}\right)$. According to the recorded spectra (Figure $5 \mathrm{~b}$ ), the position of the Raman peaks (except A1g and B1g that cannot be visible individually at room temperature) are characteristic to the anatase phase of $\mathrm{TiO}_{2}$ nanoparticles. The zeolite analyzed by Raman spectroscopy comes from Romania, extracted from the Transylvanian region (specifications detailed in the Materials section). Despite the existence of a significant number of research 
papers dealing with the Raman spectra of zeolites, the clear assignment of the peaks that appear in the spectrum remains a challenge. A method of analyzing the Raman spectrum for a zeolite can be done taking into account the $\mathrm{Si} / \mathrm{Al}$ ratio which can vary by replacing the $\mathrm{Al}$ atoms with $\mathrm{Si}$ atoms [43]. Thus, in our case where the ratio is greater than 4 , the peaks that appear are positioned at $355,7 \mathrm{~cm}^{-1}, 438.8 \mathrm{~cm}^{-1}, 973.7 \mathrm{~cm}^{-1}, 1006.5 \mathrm{~cm}^{-1}, 1058.3 \mathrm{~cm}^{-1}$, or $1090 \mathrm{~cm}^{-1}, 1146.7$ and are due to Si-O-Al and Si-O-Si vibrations. Raman peaks in the region of $1200-1510 \mathrm{~cm}^{-1}$ can be attributed to the contamination of the analyzed sample with organic compounds. For neat DS, Raman peaks in the interval of $367-475 \mathrm{~cm}^{-1}$ could be assigned to $C-C$ vibrations. The peak found at $205 \mathrm{~cm}^{-1}$ appeared due to the presence of $\mathrm{NaOH}$ in the decontamination solution. In the region of $800-1150 \mathrm{~cm}^{-1}$, the specific peaks for $\mathrm{C}-\mathrm{O}-\mathrm{C}$ bonds can be observed. The presence of isopropyl alcohol in the neat DS generated the two peaks found at $819 \mathrm{~cm}^{-1}(\mathrm{C}-\mathrm{H})$ and $1452 \mathrm{~cm}^{-1}$ (OCH bending). The peaks ranging from 2800 to $2970 \mathrm{~cm}^{-1}$ are specific for $\mathrm{C}-\mathrm{H}$ vibrations.

\subsection{Biological Decontamination}

It was found that on the sporulated forms of $B$. anthracis and also on its vegetative form, the decontamination solution showed excellent antimicrobial activity, according to Table 3. In the case of Ps. aeruginosa and the vegetative form of B. cereus and B. subtilis, we observed no logarithmic reduction on the painted metal sample, the microorganisms being too many to be counted. For $S$. aureus in vegetative form, regarding the results on all four types of surfaces, a reduction with $\log 3$ was shown, while for $B$. cereus, $B$. subtilis, and $P$. aeruginosa, a logarithmic reduction of 3 was noticed in the case of glass, rubber, and cotton butyl rubber surfaces. A substance is considered to have bactericidal effect if at least a 3Log reduction in CFU/mL or $99.9 \%$ kill is obtained over a specified time (24 h) of contact. Bactericidal effect, in some cases, can be determined at $6 \mathrm{~h}$. A 90\% kill (1Log reduction) at $6 \mathrm{~h}$ is the equivalent to a $99.9 \%$ reduction at $24 \mathrm{~h} \mathrm{[44].} \mathrm{B.} \mathrm{cereus} \mathrm{and} \mathrm{B.} \mathrm{subtilis} \mathrm{in} \mathrm{the}$ sporulated form presented a reduction of $\log 2$ on painted metal and cotton butyl rubber, and a reduction of $\log 1$ for glass and rubber. For the sporulated forms, the reduction should be between 1 and $1.5 \log$ [45] to be considered decontaminated.

All the studied suspensions demonstrated antimicrobial activity against the tested microorganisms. The MIC values of all the substances are in the range of a maximum two-fold dilution, which is quite homogeneous. This homogeneity of the MIC's, most likely, is due to the same way of the action of the substances. The most sensitive microorganism to the decontamination solutions seems to be Bacillus spizizenii. In the case of Ps. aeruginosa, the MIC values are all the same, but the MBC values are the most diverse. The time kill assay was performed only on $E$. coli and $S$. aureus. In the test condition, no signs of growth were observed for any of the microorganisms put in contact with DS, DS-TiO $2-0.5$, $\mathrm{DS}_{-} \mathrm{TiO}_{2}-1$, DS-Z-0.5, and DS-Z-1 even after $3 \mathrm{~h}$, which means an almost 6 Log decrease. In the case of the nanoparticles solutions based on DS-ZnO-0.5 and DS-ZnO-1 only after $6 \mathrm{~h}$ of contact, the same decrease was observed for both studied microorganisms. According to Konate et al. 1, a 1Log decrease after $6 \mathrm{~h}$ of contact demonstrates the bactericidal effect of a substance with antimicrobial properties. When comparing the MBC and time-kill test, the results may seem different, but we must take into account that in the case of MBC, microorganisms were in contact with nanoparticles in $\mathrm{MHb}$, a nutrient medium, and in the case of time-kill test, the microorganisms were in contact in PBS.

\subsection{Chemical Decontamination}

The decontamination tests on different surfaces represent a very useful tool to evaluate, at a small scale, an operational decontamination process. The testing method combines the requirements for the laboratory procedures with the operational ones. The samples tested represent the most common surfaces that are found near a military station: painted metal (technicals, cars, and armament), glass (goggles for a gas mask, sniper scope, and windows), rubber (protective gloves, gas mask, and gaskets), and cotton butyl rubber (individual protective equipment). 
The remnant toxic chemical concentration was evaluated by GC-MS on the neat DS and on the neat DS after being exposed to a hot-dry cycle temperature and after a cold cycle temperature. The results showed a decontamination efficiency for HD between $99.2 \%$ and $99.98 \%$ for the neat DS after $10 \mathrm{~min}$. In comparing the results of DS and DS after extreme temperature exposure, we observed a slightly increment of the remnant concentration on the surfaces, but the decontamination efficiency was still over $99 \%$ on all the surfaces with all three tested solutions, and a minimum decontamination efficiency for blister agents is required by NATO standards (Table 5). In comparing the different types of tested surfaces, we observed the expected fact that the remnant HD on porous materials such as rubber $\left(0.09 \mathrm{mg} / 10 \mathrm{~cm}^{2}\right)$ is higher than for surfaces such as glass $\left(0.0002 \mathrm{mg} / 10 \mathrm{~cm}^{2}\right)$ from an initial contamination of $10 \mathrm{mg} / 10 \mathrm{~cm}^{2}$ (Figure $8 \mathrm{a}$ ). The GD decontamination on different surfaces showed superior results of about $99.93 \%$ (rubber) to $100 \%$ (glass) (Table 5). A slightly higher concentration of remnant GD was observed on cotton butyl rubber $\left(0.01 \mathrm{mg} / 10 \mathrm{~cm}^{2}\right.$; Figure $\left.8 \mathrm{~b}\right)$ but, even so, the decontamination efficiency is higher than the $99.90 \%$, minimum decontamination efficiency required by NATO standards for nerve agents.

The procedure for decontamination on multiple surfaces implies a water rinse step, which helps the removal of the toxic chemical, a very important fact in operational decontamination. In order to evaluate the decontamination efficiency enhancement of the NPs' addition, the procedure had been changed in order to strictly evaluate the degradation on the toxic chemical and not the degradation together with the removal, as we referred to in the first procedure.

The decontamination efficiency of the decontamination formulations based on $\mathrm{ZnO}$, $\mathrm{TiO}_{2}$, and zeolite nanoparticles was evaluated after $2 \mathrm{~min}, 10 \mathrm{~min}, 30 \mathrm{~min}, 1 \mathrm{~h}, 5 \mathrm{~h}$, and $24 \mathrm{~h}$ for sulfur mustard and after $2 \mathrm{~min}, 10 \mathrm{~min}, 30 \mathrm{~min}$, and $1 \mathrm{~h}$ for soman (Figures 9-12). Suspensions of $0.5 \mathrm{wt}$. \% NPs and $1 \mathrm{wt}$. \% NPs were tested for the decontamination efficiency.

For the decontamination of HD, we observed an improvement considering the decontamination efficiency and the remnant toxic on the samples containing NPs. The neat organic DS presented a decontamination efficiency of $82.84 \%$ after $1 \mathrm{~h}$, equivalent to 172 ppm remnant HD, and of $96.27 \%$ after $5 \mathrm{~h}$, equivalent to 37 ppm remnant HD. The results obtained from the decontamination with NPs' suspensions showed an improvement of the reaction speed, with the decontamination efficiency after $1 \mathrm{~h}$ being $96.74 \%$ (DS-Z-0.5), 96.08\% (DS- $\mathrm{TiO}_{2}-0.5$ ), and 86.79\% (DS-ZnO-1; Figure 9). The equivalent of remnant HD after $1 \mathrm{~h}$ is between $33 \mathrm{ppm}$ and $132 \mathrm{ppm}$ (Figure 10). We can observe that the results obtained after $1 \mathrm{~h}$ with the NPs' suspensions of $\mathrm{TiO}_{2}$ and zeolite are almost the same as after $5 \mathrm{~h}$ with the neat organic DS. After $5 \mathrm{~h}$, the NPs' suspensions showed a decontamination efficiency of over 99\% (DS-TiO $2-0.5$, DS-Z-0.5, and DS-Z-1; Figure 9), equivalent to less than 10 ppm remnant HD, from an initial concentration of 1000 ppm HD (Figure 10).

In the case of GD decontamination, the neat organic DS presented a $98.93 \%$ decontamination efficiency after only 2 min (Figure 11), equivalent to 11 ppm (Figure 12), and 99.91\% after $1 \mathrm{~h}$, equivalent to less than $1 \mathrm{ppm}$. Even if, in the case of this nerve agent, the DS worked very fast and with a very good neutralization reaction, the NPs' suspensions showed also a faster degradation with an improved decontamination efficiency. After $2 \mathrm{~min}$, the suspensions showed decontamination efficiencies of about $99.91 \%$ (DS-ZnO-1 and $\mathrm{DS}-\mathrm{TiO}_{2}-0.5$ ) and 99.4\% (DS-Z-0.5; Figure 11), representing less than 1 ppm remnant GD (Figure 12). After $30 \mathrm{~min}$, all six NPs' suspensions tested presented a completed neutralization of the GD.

\subsection{Statistical Analysis of the Decontamination Experiments Results}

For a brief statistical evaluation of the decontamination efficiency of the solutions employed in this study, neat DS was compared with each of the nanoparticle-enriched formulations. For the decontamination efficiency of HD statistical analysis, DS was compared with each nanoparticle suspension. A threshold of significance of $\alpha=0.05$ was attributed for the validation of the statistical results and 0.95 confidence level. It was 
hypothesized $\left(\mathrm{H}_{0}\right)$ that there is no significant statistical difference between the mean values of the concentrations of the two compared samples. For this purpose, we applied the paired T-student test. From the results' analysis, in the case of the DS-ZnO-0.5 and DS-ZnO-1 comparison, the $\mathrm{P}(\mathrm{T} \leq \mathrm{t})$ two-tailed test statistics $(0.014)$ offer the possibility to obtain the absolute $t$-value (3.268) and evaluated it as being higher than the critical $t$-value (2.364). As the statistical significance value $(P)$ is lower than the threshold of significance $(\alpha)$ originally set, the initial hypothesis $\mathrm{H}_{0}$ is rejected in this case. Therefore, it results that there is a significant difference between the mean concentration values of each specimen, thus $\bar{x}$ DS-ZnO-0.5 = 265.921 and $\bar{x}$ DS-ZnO-1 = 255.919. In the case of the DS and DS-ZnO-0.5 comparison, the absolute $t$-value $(-1.260)$ is lower than the critical $t$-value $(2.364)$. The values of the statistical significance are higher than the threshold of significance $\alpha$, therefore the initial hypothesis is accepted and it can be concluded that there are no significant differences between the mean HD remanent concentrations of each sample. Table S4 from the Supplementary Material File provides the information representing that the DS-ZnO-0.5 and DS-ZnO-1 in comparison with DS are not significantly different as the mode of action on the HD and the remnant concentration of the toxicant are similar. In the case of the DS and $\mathrm{TiO}_{2}$ nanoparticle formulations, all three sets of comparisons showed a statistical significance lower than the threshold of significance initially set and the $\mathrm{H}_{0}$ hypothesis was rejected, leading to the conclusion that there is a significant difference between the measured samples. In the case of the DS and zeolite nanoparticle formulations, comparisons showed a $\mathrm{P}$ lower than $\alpha$, leading to a rejected $\mathrm{H}_{0}$ hypothesis, but the comparison of the two different zeolite formulations showed a P higher than $\alpha$, which is leading to the acceptance of the $\mathrm{H}_{0}$ hypothesis. As a conclusion, even if there is a significant difference between the $\mathrm{HD}$ remnant mean concentrations of the neat DS and each zeolite formulation, the two different concentrations of zeolite formulations showed no significant difference between them. The statistical analysis for the decontamination efficiency of GD (presented in Table S9 from the Supplementary Material File) showed, in all cases, no significant statistical difference between the mean values of the concentrations of each of the two compared samples, with the aspect that each of the two nanoparticle formulations (with the same type of nanoparticles) showed a more obvious resemblance than when they were compared to neat DS.

\section{Materials and Methods}

\subsection{Materials}

The neat DS was provided by the Research and Innovation Center for CBRN Defense and Ecology, 225 Oltenitei Ave., Bucharest, 041327, Romania. The materials they employed for the preparation of the neat decontamination solution were 2-ethoxyethanol ( $\geq 99.8 \%$, ethylene glycol monoethyl ether, Sigma Aldrich, St. Louis, USA), monoethanolamine ( $\geq 98 \%$, Sigma Aldrich, St. Louis, MO, USA), sodium hydroxide ( $\geq 98 \%$, Sigma Aldrich, St. Louis, USA), isopropyl alcohol ( $\geq 99.7 \%$, Sigma Aldrich, St. Louis, USA), and sodium lauryl sulfate (SDS, Sigma Aldrich, St. Louis, USA), and were used as received. Nanosized adsorbent $\mathrm{ZnO}$ was synthesized from zinc nitrate hexahydrate $\left(\mathrm{Zn}\left(\mathrm{NO}_{3}\right)_{2} \times 6 \mathrm{H}_{2} \mathrm{O}, \geq 98 \%\right.$, Sigma Aldrich, St. Louis, USA) and sodium hydroxide ( $\geq 97 \%$, Sigma Aldrich, St. Louis, USA). Titanium dioxide anatase phase nanoparticles were synthesized from tetrabutyl titanate (97\%, Sigma Aldrich, St. Louis, USA) and ethanol (99.8\%, Sigma Aldrich, St. Louis, USA). The micronized zeolite clinoptilolite (MZC), with an average diameter of the particles of 5 microns, was purchased from Zeolites Production S.A (Cluj-Napoca, Romania), from Rupea Zeolite Mines, located in the central region of Romania. The zeolite was subjected to sonication in isopropyl alcohol ( $\geq 99.5 \%$, Sigma Aldrich, St. Louis, USA). For the biological tests, the following biological real agents and simulants were used: Bacillus anthracis spores, Bacillus cereus spores, Bacillus subtilis (spizizenii) spores (ATCC 6633), Bacillus anthracis, Bacillus cereus, Bacillus subtilis, Staphylococcus aureus (ATCC 6538), Pseudomonas aeruginosa (ATCC 9027), and Escherichia coli (ATCC 8739). For the decontamination tests, real chemical warfare agents were utilized, including: Bis(2-chloroethyl) sulfide (HD, sulfur mustard, 
purity: 95\%, CAS: 505-60-2, Schedule 1A(4) in the Chemical Weapons Convention (CWC), own synthesis) and soman (GD, pinacolyl methylfluorophosphonate, purity $90 \%$, CAS: 96-64-0, Schedule $1 \mathrm{~A}(1)$ in the CWC, own synthesis). The samples' preparation for the GC-MS analyses involved di-chloromethane ( $\geq 99.8 \%$, DCM, Merck Millipore, Kenilworth, NJ, USA). All the tests involving the toxic agents utilized in this study were performed at the Research and Innovation Center for CBRN Defense and Ecology, in the 'Chemical Analysis Laboratory', which is an OPCW Designated Laboratory from Romania.

\subsection{Methods}

4.2.1. Synthesis of Nanosized Adsorbents for BCWA Decontamination Formulations

Zinc oxide nanoparticles

Zinc oxide nanoparticles were synthesized by using zinc nitrate hexahydrate $\left(\left(\mathrm{Zn}\left(\mathrm{NO}_{3}\right)_{2}\right.\right.$ $\times 6 \mathrm{H}_{2} \mathrm{O}$ ) and sodium hydroxide as precursors. All the reagents (analytical grade purity) were purchased from Sigma Aldrich and used as received without any further purification. Zinc nitrate hexahydrate $\left(\mathrm{Zn}\left(\mathrm{NO}_{3}\right)_{2} \times 6 \mathrm{H}_{2} \mathrm{O}(3.05 \mathrm{~g})\right)$ was added into $100 \mathrm{~mL}$ of deionized water at room temperature and $0.8 \mathrm{~g}$ of $\mathrm{NaOH}$ was added in $200 \mathrm{~mL}$ of deionized water. $\mathrm{NaOH}$ solution was slowly dropped into the vigorously stirred $\mathrm{Zn}\left(\mathrm{NO}_{3}\right)_{2}$ solution for $1 \mathrm{~h}$. A white precipitate was generated at the end of the reaction, which was collected by filtration (PTFE membrane, pores diameter of $\leq 0.5 \mu \mathrm{m}$ ). The particles obtained were washed with water and ethanol several times and dried at $80^{\circ} \mathrm{C}$ for $24 \mathrm{~h}$. $\mathrm{ZnO}$ nanostructures were obtained by annealing the as-prepared precursor at $250^{\circ} \mathrm{C}$ for $2 \mathrm{~h}$ in a tube furnace.

Titanium dioxide nanoparticles

Titanium dioxide anatase phase nanoparticles were synthesized by chemical route from solution. The raw materials from which we started were tetrabutyl titanate (Ti $\left.\left(\mathrm{OCH}_{2} \mathrm{CH}_{2} \mathrm{CH}_{2} \mathrm{CH}_{3}\right)_{4}, 97 \%\right)$ and ethanol $\left(\mathrm{CH}_{3} \mathrm{CH}_{2} \mathrm{OH}\right)$, purchased from Sigma-Aldrich. For synthesis of anatase $\mathrm{TiO}_{2}$ nanoparticles, an ethanol solution of tetrabutyl titanate was prepared $(20 \mathrm{~mL})$ and stirred for $30 \mathrm{~min}$. Tetrabutyl titanate ethanolic solution was slowly added into $20 \mathrm{~mL}$ of deionized water, vigorously stirred, and then ultrasonicated for $15 \mathrm{~min}$. The resulting precipitate was washed several times in deionized water and maintained in vacuum at room temperature for $24 \mathrm{~h}$ for the evaporation of solvent traces. Finally, the obtained titanium dioxide nanoparticles were annealed in air at $500{ }^{\circ} \mathrm{C}$ for $1 \mathrm{~h}$.

Zeolite nanoparticles

The micronized zeolite clinoptilolite (MZC) [46,47], consisting of particles with an average diameter of 5 microns, was subjected to sonication in isopropyl alcohol for $3 \mathrm{~h}$ for the disaggregation of zeolite into smaller particles in order to enhance the total active specific surface and convert it into a nanosized adsorbent. For SEM analysis, after sonication, the alcoholic dispersions were deposited by dripping on silica support and dried in an oven at $70{ }^{\circ} \mathrm{C}$. SEM analysis confirmed the accomplishment of this objective of turning zeolite into smaller nanometric particles.

\subsubsection{Biological Decontamination Tests}

To test the antimicrobial effect of the decontamination solutions, several specific methods and techniques were used corresponding to the complexity of the microbiological trials, characteristics of the decontamination formulations, and type of surface subjected to decontamination. All the microbiology assays were accomplished by following NATO standards (AEP 58 [37] and AEP 7 [48]), adapting the methods for testing polyvalent decontaminants for surfaces. Neat DS solution was tested on four different types of surfaces (metal, glass, rubber, and cotton butyl rubber) against Bacillus anthracis, Bacillus cereus, Bacillus subtilis, Staphylococcus aureus, and Pseudomonas aeruginosa. For these tests, a controlled contamination with the above enumerated microorganisms was priorly performed for each type of surface and evaluated as follows: the initial microbial load was $10^{4} \mathrm{CFU} / 10 \mathrm{~cm}^{2}$ for both spores and vegetative forms. Contamination control was performed by employing pre-moistened sterile swabs for sampling the microorganisms from the contaminated areas (measuring $10 \mathrm{~cm}^{2}$ ). The collected samples were allowed to grow on solid culture media. 
To verify contamination, colony-forming units $\left(\mathrm{CFU} / \mathrm{cm}^{2}\right)$ were counted from the surface of the solid culture media. The values counted are illustrated in Table 2. After quantifying the initial contamination, we proceeded to the decontamination step. For this purpose, several steps were done, including: pre-washing with water $\left(3 \mathrm{~mL} / 10 \mathrm{~cm}^{2}\right)$, applying decontamination solution (neat DS, $0.5 \mathrm{~mL} / 10 \mathrm{~cm}^{2}$ ), allowing for the decontamination formulation to neutralize the targeted biological agents $(10 \mathrm{~min})$, and post-washing with water $\left(3 \mathrm{~mL} / 10 \mathrm{~cm}^{2}\right)$. Decontamination control was performed by employing pre-moistened sterile swabs for sampling the microorganisms from the decontaminated areas (measuring $10 \mathrm{~cm}^{2}$ ). The collected samples were allowed to grow on solid culture media. To verify the decontamination efficiency, colony-forming units $\left(\mathrm{CFU} / \mathrm{cm}^{2}\right)$ were counted from the surface of the solid culture media. The values obtained at the completion of the decontamination are summarized in Table 3. Triplicate experiments were performed and the mean values are reported.

After the assessment of the antimicrobial activity of the neat organic solutions, the NPs-enriched decontamination solutions were also subjected to analysis for evaluating their influence on the biological decontamination capacity. Due to the presence of nanoparticles in these new decontamination solutions (nanoparticles in suspension), the minimal inhibitory concentration (MIC), minimal bactericidal concentration (MBC), and time-kill test, as detailed below, were better suited methods for the evaluation of their antimicrobial activity. The complementary assays MIC and MBC were employed for comparing the decontamination performances of NPs' suspensions and the results are depicted in Table 4.

Minimal inhibitory concentration

The antimicrobial activity of the NPs-based decontamination solutions was evaluated against Staphylococcus aureus (ATCC 6538) and Bacillus subtilis subsp. spizizenii (ATCC 6633) as a model for Gram-positive bacteria, and Escherichia coli (ATCC 8739) and Pseudomonas aeruginosa (ATCC 9027) as a model for Gram-negative bacteria. S. aureus, E. coli, and Ps. aeruginosa were chosen, being considered standard microorganisms for testing the antimicrobial properties of newly synthesized products [49]. After cultivation overnight in tryptic soy broth (TSB; Merck) at $37^{\circ} \mathrm{C}$ with stirring (200 rpm), the bacterial strains were harvested. Portions of the suspension were harvested by centrifugation and resuspended in phosphate buffer saline (PBS; Sigma-Aldrich). The suspensions were adjusted to approximately $10^{6} \mathrm{CFU} / \mathrm{mL}$ [50]. Minimum inhibitory concentrations (MIC) were established for each decontamination formulation by the broth microdilution method [51,52]. Two-fold serial dilution in Mueller-Hinton broth $(\mathrm{MHb})$ of each composite were performed in duplicates. Negative and positive controls were associated [53]. The inhibitory effect of the substances was evaluated starting from $50 \%$ concentration (the samples of the substances were diluted at 1:1 with $\mathrm{MHb}$ ). After diluting the sample, in each well, we added $10 \mu \mathrm{L}$ of the microorganism suspensions $\left(\sim 10^{4} \mathrm{CFU}\right)$. The same volume of the suspensions was added in the positive control wells.

Minimal bactericidal concentration

Minimal bactericidal concentration (MBC) values were also established. After the incubation period, we needed to establish MIC, specifically the content of the wells, which did not show that any visible signs of growth were plated on the appropriate agar plates. Agar plates were incubated for $48 \mathrm{~h}$ in order to reveal any surviving bacteria $[53,54]$.

Time-kill test

A portion of more concentrated bacterial strain suspensions $\left(10^{7} \mathrm{CFU} / \mathrm{mL}\right)$, prepared as previously described, were treated with the studied formulations at a final concentration of $2 \times$ MIC values and incubated at $37^{\circ} \mathrm{C}$ with continuous shaking for $3 \mathrm{~h}, 6 \mathrm{~h}$, and $24 \mathrm{~h}$. At each established time, a portion of the bacterial cultures were serial-diluted in PBS and then plated in duplicates on Mueller-Hinton agar (MHa) medium. After incubation at $37^{\circ} \mathrm{C}$ for $24 \mathrm{~h}$, the bacterial survival was evaluated.

MIC, MBC, and time -kill tests were repeated four times for assessing the reproducibility of these experiments. 


\subsubsection{Chemical Decontamination Tests}

\section{Extreme temperature exposure}

The decontamination neat solution was exposed to extreme temperature cycles, specifically for $24 \mathrm{~h}$ for each cycle, in a climatic chamber in order to test the decontamination efficiency after this exposure. Category A1 (extreme hot-dry), which is the first $24 \mathrm{~h}$ cycle, applies to areas which experience very high temperatures, namely the hot-dry deserts of North Africa, parts of the Middle East, northern India, and south-western USA. Romania belongs to the A3 (intermediate hot) area but because the Romanian army carries out military actions in areas corresponding to A1, the solutions were exposed to the corresponding extreme temperature cycle $\left(20 \ldots 49^{\circ} \mathrm{C}\right)$ and associated humidity $(3 \% \ldots 8 \%$ relative humidity). Category $\mathrm{C} 1$ (intermediate cold), which is the second $24 \mathrm{~h}$ cycle (20 $\left.\ldots-33^{\circ} \mathrm{C}\right)$, applies to those areas that experience moderately low temperatures, such as central Europe, Japan, and the central USA (AECTP-230). At the end of each temperature cycle, the efficiency of the chemical decontamination of sulfur mustard and soman on samples of different materials was tested.

Decontamination efficiency of DS on different types of surfaces

Decontamination efficiency tests were performed following the same procedure on the same types of materials (painted metal, glass, rubber, and cotton butyl rubber) using three decontamination solutions: neat DS, neat DS after A1 cycle exposure, and neat DS after $\mathrm{C} 1$ cycle exposure.

Contamination of samples with HD/GD. A $10 \mathrm{~cm}^{2}$ sample for testing (painted metal, glass, rubber, and cotton butyl rubber) was placed in a glass cuvette and contaminated

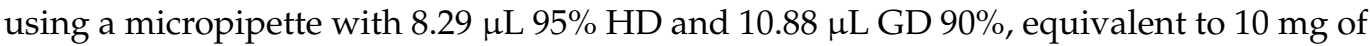
pure toxic. The toxic chemical was distributed on the surface of the sample as droplets of about 0.7 to $1 \mu \mathrm{L}$ each.

Decontamination of samples. After 30 min of contact time between the sample for testing and the toxic chemical, $0.5 \mathrm{~mL}$ of DS was pipetted from the edges to the center in continuous and thin film so that the surface was completely covered with SD. After $5 \mathrm{~min}$ of direct contact with toxic-SD, the sample was rinsed with $3 \mathrm{~mL}$ of water.

Sampling and preparation of samples for analysis. The sample was placed into a clean glass cuvette and extracted with $10 \mathrm{~mL}$ of dichloromethane (DCM) for $10 \mathrm{~min}$ under continuous stirring to ensure the best possible extraction of the remaining toxic agent. One $\mathrm{mL}$ of organic extract from the cuvette was sampled for chromatographic analysis to determine the amount of remaining toxic agent based on the calibration curve. A 5-point calibration curve was performed for each toxic, HD and GD, based on the concentration, at which the contamination was performed and also based on the maximum admitted concentration. The remnant concentration of the HD and GD after decontamination was calculated, according to AEP 58 [37].

Decontamination efficiency of NPs' suspensions

Representative NPs' suspensions and neat DS were tested for the decontamination efficiency by being put in direct contact as follows: three types of $\mathrm{NPs}\left(\mathrm{ZnO}, \mathrm{TiO}_{2}\right.$, and zeolite) were used to prepare suspensions in 2 concentrations of $0.5 \mathrm{wt} . \% \mathrm{NPs}$ and $1 \mathrm{wt}$. \% NPs. The six suspensions together with neat SD were used to decontaminate HD and GD, and the decontamination reaction was monitored and quantified after several times until the reaction was completed and the toxic chemical was completely neutralized. Five $\mathrm{mL}$ from each suspension and the neat DS were contaminated with $5.25 \mu \mathrm{L}$ of $\mathrm{HD}$ and $5.55 \mu \mathrm{L}$ GD, respectively (1000 ppm of pure toxic in suspension). Decontamination took place at room temperature under magnetic stirring. In total, $200 \mu \mathrm{L}$ of each suspension was extracted with DCM in order to be analyzed by GC-MS.

In all the decontamination experiments for evaluating the decontamination efficiency (thus calculating the decontamination factor $(\mathrm{DF})$ ), the equation employed was $\mathrm{DF}=$ $100 \cdot\left(C_{0}-C_{f}\right) / C_{0}$, where DF is the decontamination factor, $C_{0}$ is the initial concentration of the contaminant, and $\mathrm{C}_{\mathrm{f}}$ is the final concentration of the contaminant (indicating the residual contamination). 


\subsubsection{Statistical Analysis}

The decontamination experiments were run in triplicates (sample size $=3$ ) and the results are expressed as mean standard deviation (as presented in Tables S1-S3 and Tables S6-S8 from the Supplementary Material File). Statistical analysis was performed using Microsoft Excel-Data analysis tools and Origin Lab-Data analysis tools. For this purpose, the statistical evaluation of the results was assessed with the t-test-paired two samples for means, which provides a hypothesis test of the difference between population means for a pair of random samples whose differences are approximately normally distributed. The paired T-student test method was chosen due to the small size sample (less than 30). A statistical significance of $\alpha=0.05$ was attributed for the validation of the statistical results and 0.95 confidence level.

\subsection{Characterization}

The morphology and size of the synthesized nanoparticles were observed by a SEMField Emission Scanning Electron Microscope (FEG-SEM)-Nova NanoSEM 630. The characterization was performed at magnifications of $120 \mathrm{kx}, 100 \mathrm{kx}$, and $60 \mathrm{kx}$, and at acceleration voltages of $10 \mathrm{kV}$ and $15 \mathrm{kV}$ using the In-lens Secondary Electrons detector (TLD-SE). EDX mapping was fulfilled through SEM-EDX analysis performed with the aid of a Zeiss Gemini 500 microscope coupled with an XFlash 6 EDX detector from Bruker. All data from the EDX were analyzed using the ESPRIT 2 Software. Raman measurements were performed at room temperature with a Horiba micro-Raman spectrometer LabRAM HR 800, heliu-Neon Laser, which was $633 \mathrm{~nm}$ with a confocal Olympus microscope. A $100 \times$ objectiv was used to focus on $\mathrm{ZnO}$ nanoparticles' powder and Raman-scattered light was collected through the same microscope objective and detected by a cooled CCD detector. For $\mathrm{TiO}_{2}$ nanoparticles, the excitation source was a red laser $(\lambda=633 \mathrm{~nm})$ with an output power of $15 \mathrm{~mW}$ and it was focused to a spot of $\sim 0.8 \mu \mathrm{m}$. Before measurement, the system was calibrated using the $521 \mathrm{~cm}-1$ Raman line of a silicon (Si) wafer. Raman spectra for zeolite was collected with the powder placed on an $\mathrm{Au} /$ glass substrate in order to enhance Raman-scattered light. The light source was a He-Ne laser $(632.8 \mathrm{~nm})$, with the laser spot at $<1 \mu \mathrm{m}$ and $\times 100$ objective of the Olympus confocal microscope. X-ray diffraction investigations were performed using a $9 \mathrm{~kW}$ SmartLab diffractometer (Osaka, Japan) operated at $40 \mathrm{~kW}$ and $75 \mathrm{~mA}$. Powder XRD (PXRD) patterns were recorded using a step of $0.01^{\circ}$ with a speed of $5^{\circ} / \mathrm{min}$ in the $\theta / 2 \theta$ configuration. Gas chromatography mass spectrometry analyses were performed on a GC Focus-MS DSQII, Thermo Electron Corporation (Waltham, United States). GC analyses were performed on a TR5MS capillary column, with the dimensions of $30 \mathrm{~m} \times$ $0.25 \mathrm{~mm} \times 0.25 \mu \mathrm{m}$, using ultra-pure Helium (6.0), a $1 \mathrm{~mL} / \mathrm{min}$ constant flow, constant pressure, the spitless injection mode $(15 \mathrm{~mL} / \mathrm{min})$, and an injection volume of $1 \mu \mathrm{L}$. The GC temperature program consisted of $60^{\circ} \mathrm{C}(2 \mathrm{~min})$ with a heating rate of $10{ }^{\circ} \mathrm{C}$ to $300{ }^{\circ} \mathrm{C}$ (10 min). MS analyses were performed under the electron impact (EI) ionization mode at $70 \mathrm{eV}$ electron energy, with a $3 \mathrm{~min}$ solvent dela, on a scan range of $40-650 \mathrm{~m} / \mathrm{z}$. The extreme temperature cycles were performed into an Angelantoni Industrie SpA climatic chamber, specifically the DY110 model (Cimacolle, Italy).

\section{Conclusions}

This study focused on the investigation of the antimicrobial activity and degradation ability of three distinct types of nanoparticle-enriched formulations specially designed for the neutralization of real and simulated biological and real chemical warfare agents. The performances of these solutions were evaluated by simulating the operational conditions encountered on the battlefield or in a terrorist attack situation by investigating the efficiency of neutralizing real biological and chemical warfare agents from various types of surfaces (painted metal, glass, rubber, and cotton butyl rubber) that could be contaminated in the above-described scenarios.

The synthesized nanoparticles were characterized by means of SEM-EDX, XRD, and RAMAN techniques. The $\mathrm{ZnO}$ and $\mathrm{TiO}_{2}$ nanoparticles obtained displayed similar mor- 
phologies, having almost similar rounded shapes and comparable sizes. The shape of the micronized zeolite taken from Rupea (detailed in the Methods section) was reduced by ultrasonication in isopropyl alcohol and the mesoporous structure of the nanosized particles obtained was emphasized by SEM imaging. XRD offered evidence on the atomic structure of the crystals. The size, shape, and internal stress of the small crystalline regions were revealed. Raman analysis provided supplementary information about the crystalline structure of the investigated samples. Furthermore, these three nanosized adsorbents $\left(\mathrm{ZnO}, \mathrm{TiO}_{2}\right.$, and zeolite) were introduced in the neat organic solution DS, obtaining the corresponding decontamination formulations comprising $0.5 \mathrm{wt} . \%$ NPs and $1 \%$ NPs. These novel formulations were utilized for decontaminating biological agents (bacterial spores, Gram-positive bacilli, Gram-negative bacilli, and Gram-positive cocci) and chemical agents (sulfur mustard and soman). The biological decontamination efficiency was evaluated for both vegetative and sporulated forms of the tested microorganisms. The antimicrobial activity of the decontamination formulations were demonstrated by a logarithmic reduction of higher than three for the vegetative forms and higher than one for the sporulated forms. It was found that for both forms of B. anthracis, the decontamination solution showed excellent antimicrobial activity $(\mathrm{CFU}<1)$.

High decontamination factors for BCWA were obtained after only $10 \mathrm{~min}$, accomplishing the requirements imposed by NATO standards. The herein reported new decontamination formulations (neat DS) reached 100\% efficacy for Bacillus anthracis after 10-15 min, for soman after 20-30 min, and for mustard gas in an interval comprised between 5 and $24 \mathrm{~h}$ depending on the type of surface tested. For the neat DS, a decontamination efficiency for HD between $99.2 \%$ and $99.98 \%$ was obtained after only $10 \mathrm{~min}$. After extreme temperature exposure, we observed a slight increment of the remnant concentration on the surfaces, but the decontamination efficiency was still over $99 \%$ on all types of surfaces. GD underwent a faster degradation than HD. For GD, the neat DS exhibited a decontamination efficiency of $98.93 \%$ after only $2 \mathrm{~min}$. In contrast with the neat DS, NPs' suspensions showed faster and more efficient degradation of GD and HD.

The statistical analysis of the decontamination efficiency of HD showed a significant statistical difference between the values of the concentration of each two samples compared to samples involving $\mathrm{TiO}_{2}$ formulations; between neat $\mathrm{DS}$ and both $\mathrm{ZnO}$ nanoparticle formulations; and between zeolite formulations with different concentrations. The comparison between $\mathrm{ZnO}$ formulations with different concentrations and between neat DS with zeolite formulations showed no significant difference between the mean values of the HD remnant concentrations.

In the case of GD, the decontamination efficiency of all the sets of statistical comparisons showed no significant difference between the mean values of the concentrations of each of the two compared samples, with the aspect that each of the two nanoparticle formulations $(0.5 \% \mathrm{NPs}$ and $1 \% \mathrm{NPs})$ showed a more obvious resemblance between them than when they were compared with neat DS.

The limitations of this study consist of the impossibility of proving the advantages brought on by the nanoparticles in the decontamination of various types of surfaces, such as it being possible for neat DS, due to the particularities of the surfaces tested and also due to the low concentrations of NPs employed for these tests. Therefore, our future work targets include the synthesis of decontamination suspensions with higher concentrations of nanoparticles and also testing the decontamination efficiency against real biological and chemical warfare agents on different types of surfaces to evaluate the relationship between the concentration of NPs and the decontamination performances.

Performing decontamination tests on a real biological warfare agent (Bacillus anthracis) and on real chemical warfare agents (soman and sulfur mustard) allowed for an objective evaluation of the performances of the neat decontamination solution, along with the NPs' influence on the enhancement of the decontamination efficacy. The results of this study are valuable for a proper design of new decontamination formulations. 
Supplementary Materials: The following are available online at https: / / www.mdpi.com/article/ 10.3390/ph15010097/s1. Figure S1: EDX mapping results for the nanoparticle clusters: (a,d) ZnO, $(b, e) \mathrm{TiO}_{2}$ and $(\mathrm{c}, \mathrm{f})$ zeolite; Figure S2: Example of microdilution experiment for establish MIC. PS aeruginosa-MIC determination against nanoparticle solution from sample $4-\mathrm{DS}-\mathrm{TiO}_{2}-0.5$ to sample 7-DS-Z-1; Figure S3: Time-kill test verification in liquid media ( $\mathrm{MHb}$ ) for E. coli in contact with nanoparticles solution (1-7) and three different contact times (3 h, $6 \mathrm{~h}$ and $24 \mathrm{~h}$ ); Table S1: Statistical data for decontamination degrees (\%) of HD obtained for decontamination formulations: neat DS and DS containing $0.5 \%$ and $1 \% \mathrm{ZnO}$ nanoparticles; Table S2: Statistical data for decontamination degrees (\%) of HD obtained for decontamination formulations: neat DS and DS containing $0.5 \%$ and $1 \% \mathrm{TiO}_{2}$ nanoparticles; Table S3: Statistical data for decontamination degrees (\%) of HD obtained for decontamination formulations: neat DS and DS containing $0.5 \%$ and $1 \%$ Zeolite nanoparticles; Table S4: Statistical data comparing the HD remnant concentrations after decontamination with neat DS and DS containing $\mathrm{ZnO}, \mathrm{TiO}_{2}$ and zeolite nanoparticles in two different concentrations; Table S5: Mean value and variance for $\mathrm{HD}$ remnant concentration for neat DS and DS containing $\mathrm{ZnO}, \mathrm{TiO}_{2}$ and zeolite nanoparticles in two different concentrations; Table S6: Statistical data for decontamination degrees (\%) of GD obtained for decontamination formulations: neat DS and DS containing $0.5 \%$ and $1 \% \mathrm{ZnO}$ nanoparticles; Table S7: Statistical data for decontamination degrees (\%) of GD obtained for decontamination formulations: neat DS and DS containing $0.5 \%$ and $1 \% \mathrm{TiO}_{2}$ nanoparticles; Table S8: Statistical data for decontamination degrees (\%) of GD obtained for decontamination formulations: neat DS and DS containing $0.5 \%$ and $1 \%$ Zeolite nanoparticles; Table S9: Statistical data comparing the GD remnant concentrations after decontamination with neat DS and DS containing $\mathrm{ZnO}, \mathrm{TiO}_{2}$ and zeolite nanoparticles in two different concentrations; Table S10: Mean value and variance for HD remnant concentration for neat DS and DS containing $\mathrm{ZnO}, \mathrm{TiO}_{2}$ and zeolite nanoparticles in two different concentrations.

Author Contributions: Conceptualization, R.-E.G., C.L. and T.-V.T.; methodology, T.-V.T. and F.-L.Z.; software, , T.-V.T. and G.-O.I.; validation, R.-E.G., G.T. and T.-V.T.; formal analysis, R.-E.G., M.P., R.-E.O., G.-O.I., F.-L.Z., M.C., G.C., F.C., and C.R.; investigation, R.-E.G., A.-E.B., F.-L.Z., M.C., G.C., F.C., and C.R.; data curation, G.T., M.P., A.-E.B., R.-E.O., G.-O.I., F.-L.Z., M.C., G.C., F.C., and C.R.; writing-original draft preparation, R.-E.G., G.T., A.-E.B. and R.-E.O.; writing-review and editing, R.-E.G. and G.T.; supervision, M.P. and C.L.; project administration, M.P.; funding acquisition, C.L.; All authors have read and agreed to the published version of the manuscript.

Funding: This work was supported by a grant from the Ministry of Research, Innovation, and Digitization, namely CNCS/CCCDI-UEFISCDI, PN-III-P2-2.1-PED-2019-4222 ctr. no 427PED/2020.

Institutional Review Board Statement: Not applicable.

Informed Consent Statement: Not applicable.

Data Availability Statement: Data is contained within the article.

Conflicts of Interest: The authors declare no conflict of interest.

\section{References}

1. Uhm, H.S.; Lee, H.Y.; Hong, Y.C.; Shin, D.H.; Park, Y.H.; Hong, Y.F.; Lee, C.K. A decontamination study of simulated chemical and biological agents. J. Appl. Phys. 2007, 102, 013303. [CrossRef]

2. Harigel, G.G. Chemical and Biological Weapons: Use in Warfare, Impact on Society and Environment; Carnegie Endowment: Washington, DC, USA, 2001.

3. Riedel, S. Biological warfare and bioterrorism: A historical review. Bayl. Univ. Med Cent. Proc. 2004, 17, 400-406. [CrossRef] [PubMed]

4. Robertson, A.G.; Robertson, L.J. From asps to allegations: Biological warfare in history. Mil. Med. 1995, 160, 369-373. [CrossRef]

5. Cenciarelli, O. Use of Non-Pathogenic Biological Agents as Biological Warfare Simulants for the Development of a Stand-Off Detection System. J. Microb. Biochem. Technol. 2014, 06, 375-380. [CrossRef]

6. Diauudin, F.N.; Rashid, J.I.A.; Knight, V.F.; Wan Yunus, W.M.Z.; Ong, K.K.; Kasim, N.A.M.; Abdul Halim, N.; Noor, S.A.M. A review of current advances in the detection of organophosphorus chemical warfare agents based biosensor approaches. Sens. Bio-Sens. Res. 2019, 26, 100305. [CrossRef]

7. Picard, B.; Chataigner, I.; Maddaluno, J.; Legros, J. Introduction to chemical warfare agents, relevant simulants and modern neutralisation methods. Org. Biomol. Chem. R. Soc. Chem. 2019, 17, 6528-6537. [CrossRef] [PubMed]

8. Ganesan, K.; Raza, S.K.; Vijayaraghavan, R. Chemical warfare agents. J. Pharm. Bioallied Sci. 2010, 2, 166-178. [CrossRef] [PubMed] 
9. Ghabili, K.; Agutter, P.S.; Ghanei, M.; Ansarin, K.; Panahi, Y.; Shoja, M.M. Sulfur mustard toxicity: History, chemistry, pharmacokinetics, and pharmacodynamics. Crit. Rev. Toxicol. 2011, 41, 384-403. [CrossRef] [PubMed]

10. Kim, K.; Tsay, O.G.; Atwood, D.A.; Churchill, D.G. Destruction and detection of chemical warfare agents. Chem. Rev. 2011, 111, 5345-5403. [CrossRef] [PubMed]

11. OPCW. The Convention on the Prohibition of the Development, Production, Stockpiling and Use of Chemical Weapons and on Their Destruction (the Chemical Weapons Convention or CWC); OPCW: The Hauge, The Netherlands, 1997.

12. UN Office for Disarmament Affairs (UNODA). The Convention on the Prohibition of the Development, Production and Stockpiling of Bacteriological (Biological) and Toxin Weapons and on Their Destruction; 1975; Available online: https://www.un.org/disarmament/ biological-weapons / (accessed on 11 November 2021).

13. Ellison, D.H. Emergency Action for Chemical and Biological Warfare Agents; CRC Press: Boca Raton, FL, USA, 1999.

14. Frischknecht, F. The history of biological warfare. Human experimentation, modern nightmares and lone madmen in the twentieth century. EMBO Rep. 2003, 4, S47-S52. [CrossRef]

15. Toader, G.; Diacon, A.; Rotariu, T.; Alexandru, M.; Rusen, E.; Ginghină, R.E.; Alexe, F.; Oncioiu, R.; Zorila, F.L.; Podaru, A.; et al. Eco-Friendly Peelable Active Nanocomposite Films Designed for Biological and Chemical Warfare Agents Decontamination. Polymers 2021, 13, 3999. [CrossRef]

16. Wartell, M.A.; Huey, B.M. Strategies to Protect the Health of Deployed U.S. Forces: Force Protection and Decontamination; National Academies Press: Cambridge, MA, USA, 1999.

17. Prasad, G.K.; Mahato, T.H.; Pandey, P.; Singh, B.; Suryanarayana, M.V.S.; Saxena, A.; Shekhar, K. Reactive sorbent based on manganese oxide nanotubes and nanosheets for the decontamination of 2-chloro-ethyl ethyl sulphide. Microporous Mesoporous Mater. 2007, 106, 256-261. [CrossRef]

18. Prasad, G.K.; Mahato, T.H.; Singh, B.; Ganesan, K.; Srivastava, A.R.; Kaushik, M.P.; Vijayraghavan, R. Decontamination of sulfur mustard and sarin on titania nanotubes. AIChE J. 2008, 54, 2957-2963. [CrossRef]

19. Prasad, G.K.; Mahato, T.H.; Singh, B.; Pandey, P.; Rao, A.N.; Ganesan, K.; Vijayraghavan, R. Decontamination of sulfur mustard on manganese oxide nanostructures. AIChE J. 2007, 53, 1562-1567. [CrossRef]

20. Shah, S.N.; Ali, S.I.; Ali, S.R.; Naeem, M.; Bibi, Y.; Sherwani, S.K. Synthesis and Characterization of Zinc Oxide Nanoparticles for Antibacterial Applications. J. Basic Appl. Sci. 2016, 12, 205-210.

21. Singh, V.V.; Jurado-Sánchez, B.; Sattayasamitsathit, S.; Orozco, J.; Li, J.; Galarnyk, M.; Fedorak, Y.; Wang, J. Multifunctional Silver-Exchanged Zeolite Micromotors for Catalytic Detoxification of Chemical and Biological Threats. Adv. Funct. Mater. 2015, 25, 2147-2155. [CrossRef]

22. Gopinath, P.M.; Dhanasekaran, D.; Ranjani, A.; Thajuddin, N.; Akbarsha, M.A.; Velmurugan, M.; Panneerselvam, A. Optimization of sporicidal activity and environmental Bacillus endospores decontamination by biogenic silver nanoparticle. Future Microbiol. 2015, 10, 725-741. [CrossRef] [PubMed]

23. Alswat, A.A.; Ahmad, M.B.; Saleh, T.A.; Hussein, M.Z.B.; Ibrahim, N.A. Effect of zinc oxide amounts on the properties and antibacterial activities of zeolite/zinc oxide nanocomposite. Mater. Sci. Eng. C Mater. Biol. Appl. 2016, 68, 505-511. [CrossRef]

24. Sirelkhatim, A.; Mahmud, S.; Seeni, A.; Kaus, N.H.M.; Ann, L.C.; Bakhori, S.K.M.; Hasan, H.; Mohamad, D. Review on Zinc Oxide Nanoparticles: Antibacterial Activity and Toxicity Mechanism. Nano-Micro Lett. 2015, 7, 219-242. [CrossRef]

25. Gephart, R.T., 3rd; Coneski, P.N.; Wynne, J.H. Decontamination of chemical-warfare agent simulants by polymer surfaces doped with the singlet oxygen generator zinc octaphenoxyphthalocyanine. ACS Appl. Mater. Interfaces 2013, 5, 10191-10200. [CrossRef]

26. Holdren, S.; Tsyshevsky, R.; Fears, K.; Owrutsky, J.; Wu, T.; Wang, X.; Eichhorn, B.W.; Kuklja, M.M.; Zachariah, M.R. Adsorption and Destruction of the G-Series Nerve Agent Simulant Dimethyl Methylphosphonate on Zinc Oxide. ACS Catal. 2018, 9, 902-911. [CrossRef]

27. Kloffel, T.; Kozlowska, M.; Popiel, S.; Meyer, B.; Rodziewicz, P. Adsorption of sulfur mustard on clean and water-saturated $\mathrm{ZnO}(101$ 0): Structural diversity from first-principles calculations. J. Hazard. Mater. 2021, 402, 123503. [CrossRef]

28. Cojocaru, B.; Neaţu, S.; Pârvulescu, V.I.; Somoghi, V.; Petrea, N.; Epure, G.; Alvaro, M.; Garcia, H.; Garcia, H. Synergism of activated carbon and undoped and nitrogen-doped $\mathrm{TiO}_{2}$ in the photocatalytic degradation of the chemical warfare agents soman, VX, and yperite. ChemSusChem 2009, 2, 427-436. [CrossRef]

29. Petersen, E.J.; Reipa, V.; Watson, S.S.; Stanley, D.L.; Rabb, S.A.; Nelson, B.C.; Nelson, B.C. DNA damaging potential of photoactivated p25 titanium dioxide nanoparticles. Chem. Res. Toxicol. 2014, 27, 1877-1884. [CrossRef] [PubMed]

30. Subhapriya, S.; Gomathipriya, P. Green synthesis of titanium dioxide $\left(\mathrm{TiO}_{2}\right)$ nanoparticles by Trigonella foenum-graecum extract and its antimicrobial properties. Microb. Pathog. 2018, 116, 215-220. [CrossRef]

31. Nigussie, G.Y.; Tesfamariam, G.M.; Tegegne, B.M.; Weldemichel, Y.A.; Gebreab, T.W.; Gebrehiwot, D.G.; Gebremichel, G.E. Antibacterial Activity of Ag-Doped $\mathrm{TiO}_{2}$ and Ag-Doped ZnO Nanoparticles. Int. J. Photoenergy 2018, 2018, 5927485. [CrossRef]

32. De Dicastillo, C.L.; Correa, M.G.; Martínez, F.B.; Streitt, C.; Galotto, M.J. Antimicrobial Effect of Titanium Dioxide Nanoparticles. In Antimicrobial Resistance-A One Health Perspective; IntechOpen: London, UK, 2020.

33. Zaarour, M.; Dong, B.; Naydenova, I.; Retoux, R.; Mintova, S. Progress in zeolite synthesis promotes advanced applications. Microporous Mesoporous Mater. 2014, 189, 11-21. [CrossRef]

34. Sadeghi, M.; Ghaedi, H.; Yekta, S.; Babanezhad, E. Decontamination of toxic chemical warfare sulfur mustard and nerve agent simulants by NiO NPs/Ag-clinoptilolite zeolite composite adsorbent. J. Environ. Chem. Eng. 2016, 4, 2990-3000. [CrossRef] 
35. Demirci, S.; Ustaoğlu, Z.; Yılmazer, G.A.; Sahin, F.; Baç, N.; Baç, N. Antimicrobial properties of zeolite-X and zeolite-A ionexchanged with silver, copper, and zinc against a broad range of microorganisms. Appl. Biochem. Biotechnol. 2013, 172, 1652-1662. [CrossRef]

36. Sutton, S. Trending in the Environmental Monitoring Program. Am. Pharm. Rev. 2015, 18. Available online: https://www. americanpharmaceuticalreview.com/Featured-Articles/179364-Trending-in-the-Environmental-Monitoring-Program/ (accessed on 11 November 2021).

37. NATO. AEP 58-Combined Operational Characteristics, Technical Specifications, Test Procedures and Evaluation Criteria for Chemical, Biological, Radiological and Nuclear Decontamination Equipment; NATO: Brussels, Belgium, 2014.

38. Patterson, A.L. The Diffraction of X-rays by Small Crystalline Particles. Phys. Rev. 1939, 56, 972-977. [CrossRef]

39. Yoshikawa, M.; Inoue, K.; Nakagawa, T.; Ishida, H.; Hasuike, N.; Harima, H. Characterization of ZnO nanoparticles by resonant Raman scattering and cathodoluminescence spectroscopies. Appl. Phys. Lett. 2008, 92, 113115. [CrossRef]

40. Musat, V.; Fortunato, E.; Purica, M.; Mazilu, M.; Rego, A.M.B.; Diaconu, B.; Busani, T. Multifunctional zinc oxide nanostructures for a new generation of devices. Mater. Chem. Phys. 2012, 132, 339-346. [CrossRef]

41. Reghunath, S.; Pinheiro, D.; Kr, S.D. A review of hierarchical nanostructures of $\mathrm{TiO}_{2}$ : Advances and applications. Appl. Surf. Sci. Adv. 2021, 3, 100063. [CrossRef]

42. Šćepanović, M.; Grujić-Brojčin, M.; Abramović, B.; Golubović, A. Structural, morphological, and optical study of titania-based nanopowders suitable for photocatalytic applications. J. Phys. Conf. Ser. 2017, 794, 012003. [CrossRef]

43. Wang, T.; Luo, S.; Tompsett, G.A.; Timko, M.T.; Fan, W.; Auerbach, S.M. Critical Role of Tricyclic Bridges Including Neighboring Rings for Understanding Raman Spectra of Zeolites. J. Am. Chem.Soc. 2019, 141, 20318-20324. [CrossRef] [PubMed]

44. Konaté, K.; Mavoungou, J.F.; Lepengué, A.N.; Aworet-Samseny, R.R.; Hilou, A.; Souza, A.; Dicko, M.H.; M’Batchi, B. Antibacterial activity against $\beta$ - lactamase producing Methicillin and Ampicillin-resistants Staphylococcus aureus: Fractional Inhibitory Concentration Index (FICI) determination. Ann. Clin. Microbiol. Antimicrob. 2012, 11, 18. [CrossRef]

45. Russell, A.D. Bacterial spores and chemical sporicidal agents. Clin. Microbiol. Rev. 1990, 3, 99-119. [CrossRef] [PubMed]

46. Cerbu, C.; Ilas, V.A.; Czopowicz, M.; Potarniche, A.V.; Bodart-Nieva, E.P.; Muresan, E.A.; Kaba, J.; Spinu, M.; Pall, E. The Use of Activated Micronized Zeolite Clinoptilolite as a Possible Alternative to Antibiotics and Chestnut Extract for the Control of Undifferentiated Calf Diarrhea: An In Vitro and In Vivo Study. Animals 2020, 10, 2284. [CrossRef]

47. Neag, E.; Török, A.I.; Tanaselia, C.; Aschilean, I.; Senila, M. Kinetics and Equilibrium Studies for the Removal of Mn and Fe from Binary Metal Solution Systems Using a Romanian Thermally Activated Natural Zeolite. Water 2020, 12, 1614. [CrossRef]

48. NATO. AEP-7-Chemical, Biological, Radiological and Nuclear (CBRN) Contamination Survivability Factors in the Design, Testing and Acceptance of Military Equipment; NATO: Brussels, Belgium, 2012.

49. Borges, A.; Abreu, A.C.; Ferreira, C.; Saavedra, M.J.; Simoes, L.C.; Simoes, M. Antibacterial activity and mode of action of selected glucosinolate hydrolysis products against bacterial pathogens. J. Food Sci. Technol. 2015, 52, 4737-4748. [CrossRef]

50. Cui, Y.; Oh, Y.J.; Lim, J.; Youn, M.; Lee, I.; Pak, H.K.; Park, W.; Jo, W.; Park, S. AFM study of the differential inhibitory effects of the green tea polyphenol (-)-epigallocatechin-3-gallate (EGCG) against Gram-positive and Gram-negative bacteria. Food Microbiol. 2012, 29, 80-87. [CrossRef]

51. CLSI. Methods for Dilution Antimicrobial Susceptibility Tests for Bacteria That Grow Aerobically; Approved Standard-Ninth Edition; CLSI: Wayne, PA, USA, 2012.

52. De Brucker, K.; Delattin, N.; Robijns, S.; Steenackers, H.; Verstraeten, N.; Landuyt, B.; Luyten, W.; Schoofs, L.; Dovgan, B.; Frohlich, M.; et al. Derivatives of the mouse cathelicidin-related antimicrobial peptide (CRAMP) inhibit fungal and bacterial biofilm formation. Antimicrob. Agents Chemother. 2014, 58, 5395-5404. [CrossRef] [PubMed]

53. Wiegand, I.; Hilpert, K.; Hancock, R.E. Agar and broth dilution methods to determine the minimal inhibitory concentration (MIC) of antimicrobial substances. Nat. Protoc. 2008, 3, 163-175. [CrossRef] [PubMed]

54. Forry, S.P.; Madonna, M.C.; López-Pérez, D.; Lin, N.J.; Pasco, M.D. Automation of antimicrobial activity screening. AMB Express 2016, 6, 20. [CrossRef] [PubMed] 